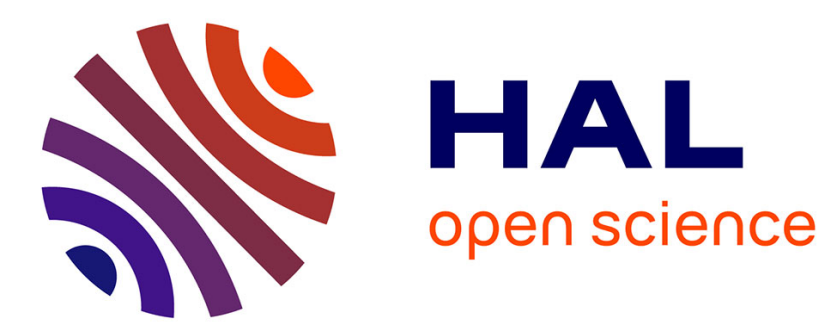

\title{
Viscoelastic potential-induced changes in acoustically thin films explored by quartz crystal microbalance with motional resistance monitoring
}

Jéronimo Agrisuelas, Claude Gabrielli, J.J. García-Jareño, Hubert Perrot, Ozlem Sel, Francisco Vicente

\section{To cite this version:}

Jéronimo Agrisuelas, Claude Gabrielli, J.J. García-Jareño, Hubert Perrot, Ozlem Sel, et al.. Viscoelastic potential-induced changes in acoustically thin films explored by quartz crystal microbalance with motional resistance monitoring. Electrochimica Acta, 2015, 176, pp.1454-1463. 10.1016/j.electacta.2015.07.131 . hal-01197075

\section{HAL Id: hal-01197075 \\ https://hal.sorbonne-universite.fr/hal-01197075}

Submitted on 11 Sep 2015

HAL is a multi-disciplinary open access archive for the deposit and dissemination of scientific research documents, whether they are published or not. The documents may come from teaching and research institutions in France or abroad, or from public or private research centers.
L'archive ouverte pluridisciplinaire HAL, est destinée au dépôt et à la diffusion de documents scientifiques de niveau recherche, publiés ou non, émanant des établissements d'enseignement et de recherche français ou étrangers, des laboratoires publics ou privés. 
Viscoelastic potential-induced changes in acoustically thin films explored by quartz crystal microbalance with motional resistance monitoring

J. Agrisuelas*,1, C. Gabrielli' ${ }^{2,3}$, J. J. García-Jareño ${ }^{1}$, H. Perrot ${ }^{2,3}$, O. Sel $^{2,3}$ and F. Vicente ${ }^{1}$

${ }^{1}$ Departament de Química Física, Universitat de València. C/ Dr. Moliner, 50, 46100, Burjassot, València, Spain

2 Sorbonne Universités, UPMC Univ Paris 06, UMR 8235, Laboratoire Interfaces et Systèmes Electrochimiques, F-75005, Paris, France

${ }^{3}$ CNRS, UMR 8235, LISE, F-75005, Paris, France

*E-mail: jeronimo.agrisuelas@uv.es 


\begin{abstract}
Viscoelastic properties of intrinsically conducting polymers depend on different factors, among them polymer structure, ionic and solvent population and film thickness. During a voltammetric cycle, electrochemical reactions involve changes of these factors. Consequently, the viscoelastic properties are expected to be changed. Electrochemical quartz crystal microbalance with motional resistance monitoring were employed to calculate the instantaneous resonant frequency/motional resistance ratio $\left(\mathrm{d} f_{r} / \mathrm{d} R_{m}\right)$ during the electrochemical processes of acoustically thin films of poly(o-toluidine). $\mathrm{d} f_{r} / \mathrm{d} R_{m}$ is defined as the energy dissipation factor and shows values around $\sim 10 \mathrm{~Hz} \Omega^{-1}$ for a net liquid-loading effect on resonator electrode. Therefore, as this value is larger the film deposited on resonator electrode is expected to be more rigid. The experimental results showed in this work points to this assumption. Viscoelastic state of acoustically thin films of poly(o-toluidine) were investigated through redox reactions, in different electrolytes and scan rates potential perturbations. Finally, viscoelastic changes of a relaxed POT and packed POT was compared. The viscoelastic aspects of poly(otoluidine) here investigated can help to understand and adjust the signal transduction of (bio)sensors or for composite supercapacitors where the mechanical properties of the different organic layers can limit the performances of the electrochemical system.
\end{abstract}

Keywords: Poly(o-toluidine); Viscoelastic properties; Electrochemical quartz crystal microbalance; Motional resistance. 


\section{INTRODUCTION}

Intrinsically conducting polymers (ICP) are one of the most versatile organic materials because their $\pi$ electron delocalisation endows them with special electrical properties [1-4]. Both film thickness and bulk density can alter during electrochemical reactions of ICP films. Thickness changes to store inserted ions or water molecules by molecular arrangements during the electrochemical transitions [5-8] as well as the bulk density considering the polymeric chains, counter-ions and water molecules condensed in a finite space (dense film) [9-11]. These changes affect the viscoelastic properties of ICP. Therefore, viscoelasticity depends on the electrolyte composition, redox state of the polymer, and the solvent incorporated into polymer network, which acts as a plasticiser [10,12-14].

Quartz crystal microbalance (QCM) has been employed for physical, chemical and biological sensing applications taking advantage of standing shear wave generated across the crystal thickness at the $a c$-voltage excitation frequency [15-17]. The acoustic energy of the wave inserted in surface-immobilised coatings involves mechanical deformations. Like seismic waves are used for researching the structure of the Earth's interior, the resonant response of the coating provides information about their viscoelastic nature.

Different acoustic resonant responses have been obtained by using ICP. In thick and/or viscous coatings, the upper film surface in contact with the solution oscillates outof-phase with the lower film surface in contact with the quartz resonator [18-20]. Rarely, the polymer|solution interface reflects the acoustic wave launched by quartz resonator (film resonance). The result is a constructive interference between the outgoing wave from the electrode|polymer interface and the reflected wave [20,21]. On other situations, the acoustic wave generated moves in-phase with the acoustic wave crossing a uniform, elastic and thin film (acoustically thin film) [20,22]. In these conditions, Sauerbrey developed theoretically how the decrease in resonant frequency, $\Delta f_{r}$, shows a linear relationship with the electrode mass shift, $\Delta m$ [23]. Later, Etchenique et al. showed the possibility of making gravimetric use of the QCM beyond the Sauerbrey limit using the Martin's viscoelastic model [24].

Actually to obtain viscoelastic information, the composite resonator must be modelled as an electrical equivalent circuit, known as the Butterworth-Van Dyke (BVD) circuit [25]. This important additional information is gained by the use of network analysers instead of a cheaper oscillator circuits which are more convenient 
configurations for determining electrogravimetric information [26]. The simplest BVDbased circuit consists of two branches that represent a static capacitance $\left(C_{S}\right)$ in parallel with a motional branch with the motional inductance, $L_{m}$, the motional capacitance, $C_{m}$, and the motional resistance $R_{m}$ in series. In detail, $R_{m}$ describes the energy dissipation during oscillation caused by internal friction, mechanical losses in the mounting system and acoustical losses to the surrounding environment [27]. The versatility of $R_{m}$ provides information on the viscoelastic effects, magnetic properties, molecular interactions, film porosity, metal conversions or electrocatalysis [28-33]. Moreover, $R_{m}$ allows the resonant frequency changes affected by viscous film coats to be estimated [34].

Viscoelastic properties of acoustically thin ICP films have been widely investigated $[10,13,19,34-38]$. However, viscoelastic parameters seem difficult to be extracted by BVD analysis because the resonant response is essentially gravimetric [21]. The viscoelastic effects are expected to have a low influence on the resonant frequency response on the contrary than in case of thicker films [13,39]. In general, film thickness $\left(h_{f}\right)$ or the film density $\left(\rho_{f}\right)$ has to be assumed constant in the viscoelastic models to extract information from the acoustic impedance [13,40,41].

An approximation to the viscoelasticity of coatings is provided by the analysis of the acoustic wave dissipation $\left(R_{m}\right)$ showed by these materials. Firstly, we consider that the acoustic wave generated by the quartz resonator traverses various physical barriers in the normal direction of the multi-layer composite resonator involving energy dissipation: the quartz crystal together with the gold electrode (q), the quartz|film interface (q|f), the acoustically thin film (f), the film|solution interface (f|s) and, finally the acoustic wave is damped in the liquid solution (s).

Thus, $R_{m}$ can be expressed as a sum of contributions from each layer and interface which the acoustic wave crosses [29,42-45]:

$$
R_{m}=R_{m}(\mathrm{q})+R_{m}(\mathrm{q} \mid \mathrm{f})+R_{m}(\mathrm{f})+R_{m}(\mathrm{f} \mid \mathrm{s})+R_{m}(\mathrm{~s})
$$

During the electrochemical transitions of an acoustically thin film, it is very feasible to assume that the variations of quartz $R_{m}(\mathrm{q})$ and solution $R_{m}$ (s) are practically negligible for each experiment carried out with a particular electrode. So, we can eliminate both contributions by the time-derivative Eq. (1):

$$
\frac{\mathrm{d} R_{m}}{\mathrm{~d} t}=\frac{\mathrm{d}\left(R_{m}(\mathrm{q} \mid \mathrm{f})+R_{m}(\mathrm{f})+R_{m}(\mathrm{f} \mid \mathrm{s})\right)}{\mathrm{d} t}
$$

Consequently, Eq. (2) only shows the variation of $R_{m}$ due to changes of the ICP physic properties. In the quartz|film interface, the adsorption forces hold the film on the 
electrode surface. The transmission of acoustic wave from the electrode surface to the film depends on these forces. In the film|solution interface, the film roughness defines the friction between the film surface and the liquid [20,46]. Formation and destruction of covalent bonds in the macromolecular backbone changes the polymer structure of ICP during the potential sweep. Therefore, film structure drives the change of $R_{m}$ in both interfaces, namely $R_{m}(\mathrm{q} \mid \mathrm{f})$ and $R_{m}(\mathrm{f} \mid \mathrm{s})$.

On the other hand, the charge carriers in the polymeric backbone, ions and free water population involve attractive or repulsive electrostatic interactions among them. Theoretically, strong attractive interactions should increase the film stiffness but, on the contrary, highly hydrated films should behave as a viscous material [10]. The polymer structure and species population inside ICP films drive the change of $R_{m}(\mathrm{f})$ by variations of the intensity of these interactions.

In 1995, Muramatsu et al. analysed the Sauerbrey model through the relationship between $\Delta R_{m}$ and $\Delta f_{r}$ of viscoelastic films [47]. They proposed a region on the plotted $\Delta R_{m}$ and $\Delta f_{r}$ diagram where the relation between the real mass changes and resonant frequency is reliable. In this region, $\Delta f_{r} / \Delta R_{m}$ ratios are equal or greater than $100 \mathrm{~Hz} \Omega^{-1}$. For uncoated resonators, the characteristic ratio of a net density/viscosity effect, which is, in fact, a characteristic of a net liquid-loading effect is $\sim 10 \mathrm{~Hz} \Omega^{-1}$ [42]. Therefore, it is expected in thin ICP that the larger the absolute value of $\mathrm{d} f_{r} / \mathrm{d} R_{m}$ the weaker the density/viscosity effect. In consequence, the resonant frequency change will be caused only by a real mass change, which falls in the gravimetric quartz crystal resonator response [48-50].

Muramatsu et al. defined $\mathrm{d} f_{r} / \mathrm{d} R_{m}$ as the energy dissipation factor or viscoelasticity factor of coated film [37,51]. They used the evolution of $\mathrm{d} f_{r} / \mathrm{d} R_{m}$ to identify the phase transition of thin polymer films during cooling-heating cycles. At lower temperature, the polymer showed the higher values of $\mathrm{d} f_{r} / \mathrm{d} R_{m}$. It is expected that the polymer was in its more rigid state. This is difficult to obtain in polymers immersed in a solution because temperature affects the electrolyte viscosity [10]. Based on these assumptions, $\mathrm{d} f_{r} / \mathrm{d} R_{m}$ may be used to evaluate the viscoelastic state of the coating film even in the gravimetric regime: the larger $\mathrm{d} f_{r} / \mathrm{d} R_{m}$ the stiffer the film.

The combined analysis of both magnitudes has also reported alternative information. Lucklum et al. described a model analysing $\Delta R_{m}$ and $\Delta f_{r}$ of a quartz 
resonator to demonstrate the usefulness to calculate thickness of viscoelastic films [50]. Moreover, $\mathrm{d} f_{r} / \mathrm{d} R_{m}$ also allowed the coupling of biomolecules to be monitored [52].

The aim of this work is to demonstrate the usefulness of $\Delta f_{r} / \Delta R_{m}$ or $\mathrm{d} f_{r} / \mathrm{d} R_{m}$ ratio to study the evolution of viscoelastic changes during the electrochemical reactions of acoustically thin films. For that, the electrochemical Quartz Crystal Microbalance with motional Resistance monitoring (QCM-R) was employed. QCM-R allows high-speed acquisition of resonant frequency and motional resistance to be obtained simultaneously. Acoustically thin poly(o-toluidine) (POT) films were studied in different electrochemical scenarios. Changes of $\Delta f_{r} / \Delta R_{m}$ or $\mathrm{d} f_{r} / \mathrm{d} R_{m}$ were evaluated during POT electrosynthesis and during the electrochemical reactions of POT at different scan rates, with different dopant anions and during the electrochemical relaxation by using cyclic voltammetry. We have studied POT films by cyclic spectroelectrogravimetry and ac-electrogravimetry in previous works[53-57]. Therefore, we have a strong background to understand the viscoelastic states of acoustically thin films of POT using $\Delta f_{r} / \Delta R_{m}$ or $\mathrm{d} f_{r} / \mathrm{d} R_{m}$ ratios.

Poly(o-toluidine) (POT) thin films is a polyaniline-like derivate with $-\mathrm{CH}_{3}$ groups on benzene rings. To the best of our knowledge, limited literature is found about some aspect of viscoelastic properties of POT [58]. On the contrary, electrochemical properties were extensively studied [59-63]. The random distribution of $-\mathrm{CH}_{3}$ groups in the polymer backbone provides the POT polymer a greater electron location than the polyaniline parent [64]. Therefore, POT can form two time-stable conducting configurations: the polaronic lattice $(\mathrm{P})$ formed mainly by polarons centres and the bipolaronic lattice (BP) formed mainly by bipolarons centres. This fact is the main reason to select this polymer.

Three consecutives steps during the electrochemical reactions of POT in aqueous acid solutions have been identified in previous works [53,54]:

$$
\begin{aligned}
& \mathrm{LE}+\mathrm{A}^{-\stackrel{-\mathrm{e}^{-}}{\rightleftarrows}} \stackrel{+\mathrm{e}^{-}}{\rightleftarrows} \mathrm{P}+\mathrm{H}_{2} \mathrm{O} \\
& \mathrm{P}+\mathrm{A}^{-\stackrel{-\mathrm{e}^{-}}{\rightleftarrows}} \stackrel{\mathrm{e}^{-}}{\rightleftarrows} \mathrm{BP}+\mathrm{H}_{2} \mathrm{O}
\end{aligned}
$$

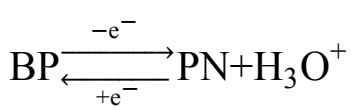

where LE is the reduced film or leucoemeraldine, $\mathrm{PN}$ is the oxidised film or pernigraniline and $\mathrm{A}^{-}$is the anion for charge balance. $\mathrm{LE} \rightleftarrows \mathrm{P}$ transitions (Eq. (3)) and $\mathrm{P} \rightleftarrows \mathrm{BP}$ transitions (Eq. (4)) are faster than the deprotonation/protonation process (BP $\rightleftarrows \mathrm{PN}$ transitions of Eq. (5)). During the electrochemical transitions, fast conformational changes and anion 
transfer control fast water molecule transfers [65]. The different lattices presented by POT can be considered as single entities with specific and independently measurable electrochemical properties.

\section{EXPERIMENTAL}

Electrochemical polymer deposition and characterization were controlled by cyclic voltammetry (CV) through an AUTOLAB potentiostat-galvanostat set up (PGSTAT302) and a QCM-R (RQCM, Maxtek Inc.). QCM-R was calibrated by means of galvanostatic copper electrodeposition. The experimental solution of test was $0.5 \mathrm{M}$ $\mathrm{CuSO}_{4}, 0.1 \mathrm{M} \mathrm{H}_{2} \mathrm{SO}_{4}$, and $\mathrm{pH}$ 1.92. The experimental Sauerbrey constant was $7.04 \mathrm{ng}$ $\mathrm{Hz}^{-1} \mathrm{~cm}^{-2}$ for a $9 \mathrm{MHz}$ quartz crystal (Matel-Fordahl, France).

The three-electrode cell involves an $\mathrm{Ag}|\mathrm{AgCl}| \mathrm{KCl}_{\text {sat }}$ reference (RE-1C, Bas Inc., Japan), a platinum wire counter electrode and the working electrode was a high reflectance gold electrode with piezoelectrically and electrochemically active areas of 0.2 $\mathrm{cm}^{2}$ and $0.3 \mathrm{~cm}^{2}$, respectively. The polymerization solution was $0.5 \mathrm{M} \mathrm{H}_{2} \mathrm{SO}_{4}$ (Fisher scientific, for trace analysis) and 0.2 M o-toluidine (Fluka) used as received. All solutions were prepared with deionized and double-distilled water. POT was formed through 100 voltammetric cycles between $-0.1 \mathrm{~V}$ and $0.9 \mathrm{~V}$ with a scan rate of $100 \mathrm{mV} \mathrm{s}^{-1}$. Thin POT films of about $350 \mathrm{~nm}$ were obtained considering the o-toluidine density $\left(1.01 \mathrm{~g} \mathrm{~cm}^{-3}\right)$ and mass deposited $\left(35 \mu \mathrm{g} \mathrm{cm}^{-2}\right)$ [10]. The resulting films has an open structure owing to the properties of bisulphate anions [66].

Cyclic electrogravimetry characterization was performed between -0.2 or $-0.1 \mathrm{~V}$ and $0.7 \mathrm{~V}$ in a free-monomer aqueous solution: $0.5 \mathrm{M} \mathrm{H}_{2} \mathrm{SO}_{4} ; 0.5 \mathrm{M} \mathrm{HNO}_{3}$ (Normapur AnalR) or $0.5 \mathrm{M} \mathrm{HClO}_{4}$ (Normapur RP). Previously to the voltammogram, the initial potential was applied during $15 \mathrm{~s}$. Three cyclic voltammograms were necessary to obtain a stable and relaxed POT film [67]. The restriction to the anodic limit potential exclude the possibility of a film electrochemical degradation by hydrolysis [68]. A home-made Peltier temperature controller stabilized the temperature of electrochemical cell at 299.2 K. All collected data were smoothed leaving out the noise by standard mathematical routines of the Mathcad 14 software (Mathsoft). $\Delta f_{r}$ and $\Delta R_{m}$ were calculated as a difference between any value and the first values of film deposition or cyclic voltammetry following these equations: $\Delta f_{r}=f_{r}-f_{r_{o}}$ and $\Delta R_{m}=R_{m}-R_{m_{o}}$. In this manner, $\Delta f_{r}$ and $\Delta R_{m}$ show same tendencies than that of raw values ( $f_{r}$ and $R_{m}$, respectively). 


\section{RESULTS AND DISCUSSION}

\subsection{Electrosynthesis}

POT films were electrosynthesised by repetitive cyclic voltammetry. The increasing current response in voltammograms suggests the growth of the POT on the resonator (Fig. 1). The free monomer radicalisation typically occurs close to $0.9 \mathrm{~V}$ to form polymeric chains whereas POT electrochemical response takes place between $0 \mathrm{~V}$ and $0.7 \mathrm{~V}$. Fig. 1 shows that POT produced is a typical film of those studied elsewhere by cyclic voltammetry and it does not provide novel claims. However, the analysis of resonant frequency and motional resistance results allows a first approximation to the evolution of viscoelastic states of deposited film to be analysed during the electrosynthesis.

From results observed in other works [21,47], it is expected that the acoustic wave has more difficulties to cross the film as the POT grows because viscoelastic properties could change progressively after each cycle. To check such changes, Fig. 2 gives $\Delta f_{r}$ evolution over $\Delta R_{m}$ evolution during the polymer deposition. The results show a response with two components, consisting of a monotonically one and an oscillatory one. On the one hand, the reversible electrochemical transitions of POT deposited in previous cycles cause the oscillatory responses. We can see a detailed oscillatory response during the $70^{\text {th }}$ cycle in the inset of Fig. 2. On the other hand, POT deposition causes the monotonical downward response. As the analysis of oscillatory response will be discussed in Section 3.2 during a cyclic voltammogram without monomers in solution, we focus the analysis on the monotonical response.

For a bare $9 \mathrm{MHz}$ quartz crystal resonator, $R_{m}$ in air and in $0.5 \mathrm{M} \mathrm{H}_{2} \mathrm{SO}_{4}$ solution are $\sim 30$ and $\sim 270 \Omega$, respectively with a decrease of $f_{r}$ about $2400 \mathrm{~Hz}$. Therefore, $\left|\Delta f_{r} / \Delta R_{m}\right|$ is $\sim 10 \mathrm{~Hz} \Omega^{-1}$, which is the characteristic value of a net density/viscous effect [42]. At early stages of polymerisation, the slope of monotonical response is close to this characteristic ratio (line A in Fig. 2) [42]. Therefore, $\Delta R_{m}$ per cycle is higher than $\Delta f_{r}$ per cycle. This fact could be due to:

i) deposited POT film could involve the formation of small polymer nuclei spread on the surface of resonator. As a result, the voids among nuclei filled by solution involve an extra volume of liquid displaced by the roughness affecting $R_{m}$ [20].

ii) alternatively, if POT is a homogenous coating uniformly deposited during the cyclic voltammetry, then, the semi-infinite Newtonian liquid damps the acoustic wave 
after crossing an ultrathin POT film below $35 \mathrm{~nm}\left(\Delta f_{r}<500 \mathrm{~Hz}\right)$ considering monomer density [13].

Unfortunately, we are unable to decide between one alternative or both from these results. However, it is clear that the viscous/density effect of solution hides the evaluation of POT viscoelasticity by the $\left|\Delta f_{r} / \Delta R_{m}\right|$ ratio.

Afterwards, the slope of monotonical response increases to $-46 \mathrm{~Hz} \Omega^{-1}$ (line B in Fig. 2) where it is nearly constant up to the end of the electrosynthesis. This linear relationship between $\Delta f_{r}$ and $\Delta R_{m}$ showed at last cycles of electrodeposition is significantly larger than $-10 \mathrm{~Hz} \Omega^{-1}$. Therefore, we can consider that deposited POT is inside the gravimetric regime of QCM-R. In other words, electrosynthesised POT is an acoustically thin film because it couples the acoustic wave. This result means that the general viscoelastic state of deposited POT are keeping constant in spite of increasing layer deposition. However, a slope of $-46 \mathrm{~Hz} \Omega^{-1}$ is far from reached values by more rigid films like the inorganic Prussian Blue polymer (Line C in Fig. 2) [29]. Most probably, the viscoelastic properties of POT will change when electrodeposition process exceeds more than 100 cycles. Then, we could expect that the slope of monotonical response comes closer to values of viscous materials [47].

\subsection{Cyclic voltammetry}

Typically, the electrochemical response of a relaxed POT in $0.5 \mathrm{M} \mathrm{H}_{2} \mathrm{SO}_{4}$ aqueous solution without monomer at $10 \mathrm{mV} \mathrm{s}^{-1}$ between $-0.2 \mathrm{~V}$ and $0.7 \mathrm{~V}$ is showed in Fig. 3. Usually, a relaxed film of POT is achieved after two or three voltammetric cycles. This film shows two couple of peaks. $\mathrm{LE} \rightleftarrows \mathrm{P}$ transitions in Eq. (3) take place around 0.15-0.25 $\mathrm{V}$ and $\mathrm{BP} \rightleftarrows \mathrm{PN}$ transitions in Eq. (5) are around 0.6-0.65 V. In both processes, the nonconductor entities of the film (LE or PN) take part. On the contrary, $\mathrm{P} \rightleftarrows \mathrm{BP}$ transitions in Eq. (4) occur at intermediate potentials without an apparent well-defined pair of peaks because $\mathrm{P}$ and $\mathrm{BP}$ are conductive entities [53].

In this voltammetric cycle, we obtain a $\left|\Delta f_{r} / \Delta R_{m}\right|$ ratio of about $45 \mathrm{~Hz} \Omega^{-1}$ between the reduced (LE) and the oxidised (PN) POT film (Fig. 4a). This ratio agrees the ratio obtained in Fig. 2. Therefore, we are in the gravimetric response of the quartz resonator because POT viscoelasticity is enough to couple the ultrasonic oscillations. However, POT involve $\Delta f_{r}$ and $\Delta R_{m}$ changes during the voltammetric cycle (Fig. 4a). We can use the instantaneous changes of $f_{r}$ and $R_{m}$ to evaluate the changes of POT viscoelastic states driven by the intermediate electrochemical transitions. 
Fig. $4 \mathrm{~b}$ gives the results of crossing instantaneous and synchronised data of $f_{r}$ and $R_{m}$. In a first sight, $\mathrm{d} f_{r} / \mathrm{d} R_{m}$ points out to different viscoelastic states among the three electrochemical transitions and between oxidation and reduction reactions. We must be cautious about the interpretation of $\mathrm{d} f_{r} / \mathrm{d} R_{m}$ in all voltammetric cycle because of the complexity of electrochemical system. However in three characteristics zones and eight characteristics points, we can approximate the viscoelastic state with changes of polymer structure, ion/free water population and thickness using the results obtained in previous works $[53,55]$.

Zone I. $\mathrm{d} f_{r} / \mathrm{d} R_{m}$ increases from $+27 \mathrm{~Hz} \Omega^{-1}$ at $0.15 \mathrm{~V}$ to $+135 \mathrm{~Hz} \Omega^{-1}$ at 0.435 V (Fig. 4b). That means POT stiffness increases. During the film oxidation, the number of polarons increases stabilised by $\mathrm{HSO}_{4}^{-}$insertion to form coil structure. Simultaneously, free water expulsion takes place. Despite film dehydration, film thickness increases because the anions cannot exclude the equivalent 4 molecules of $\mathrm{H}_{2} \mathrm{O}$ if the theoretical volume of both molecules are considered. Strong interactions between polarons and $\mathrm{HSO}_{4}^{-}$to form coil structures, repulsions between neighbour centres and dehydration of film are the responsible of the increasing stiffness.

Perusal the bibliography, as far as we know, few evidences contrast our results. However, Hillman et al. observed an increasing stiffness as anions are inserted and water molecules are expelled from an PANI films during the $\mathrm{LE} \rightarrow \mathrm{P}$ transition $[10,13] . \mathrm{d} f_{r} / \mathrm{d} R_{m}$ evolution in zone I of Fig. 4b agrees the results obtained in that work. In the reverse transition ( $\mathrm{LE} \rightarrow \mathrm{P}$ transition) in PANI films, the original viscoelasticity of film is recovered as it approximately occurs for POT films where $\mathrm{d} f_{r} / \mathrm{d} R_{m}$ returns to values about $+50 \mathrm{~Hz} \Omega^{-1}$ around $0.1 \mathrm{~V}$ (Fig. 4b).

As the potential increases, charge carriers destabilises the $\mathrm{P}$ centres stimulating the formation of BP centres (around $0.3 \mathrm{~V}$ ). Then, $\mathrm{d} f_{r} / \mathrm{d} R_{m}$ reaches $+135 \mathrm{~Hz} \Omega^{-1}$ at 0.435 $\mathrm{V}$ where POT has a P-BP mixed lattice. This potential coincides with the final increment of the film thickness reached by the $\mathrm{LE} \rightarrow \mathrm{P}$ transition and the maximum rate of change of $\Delta d_{f}^{\prime}$ during the $\mathrm{P} \rightarrow \mathrm{BP}$ transition. Henceforth, the deprotonation process of POT structure begins by oxidation of BP centres to form PN centres. Consequently, POT stiffness decrease rapidly between $0.435 \mathrm{~V}$ and $0.5 \mathrm{~V}$ despite POT thickness decreases.

Zone II. From $0.580 \mathrm{~V}$ to $0.7 \mathrm{~V}$ in the oxidation direction in Fig. 4b, POT shows a quasi-viscous state. In this potential range, $\mathrm{d} f_{r} / \mathrm{d} R_{m}$ is constant and close to $-15 \mathrm{~Hz}$ $\Omega^{-1}$. At $0.580 \mathrm{~V}$, the maximum flux of $\mathrm{H}_{3} \mathrm{O}^{+}$expulsion takes place and $\mathrm{P} \rightarrow \mathrm{BP}$ transition 
is over. Moreover, film thickness decreases during the $\mathrm{BP} \rightarrow \mathrm{PN}$ transition. Deprotonation and anion insertion with expulsion of water reduces drastically the POT stiffness. Moreover, this transition involves attractive interactions between BP centres after being protonated.

On the contrary, $\mathrm{H}_{3} \mathrm{O}^{+}$insertion and the consequent formation of $\mathrm{BP}$ centres in POT during the $\mathrm{PN} \rightarrow \mathrm{BP}$ transition shows $\mathrm{d} f_{r} / \mathrm{d} R_{m}$ values close to $-40 \mathrm{~Hz} \Omega^{-1}$ (Fig. $4 \mathrm{~b}$ ). Attractive interactions between BP centres contribute to stiffen the polymer during the protonation process of POT. It is possible that acid $\mathrm{pH}$ of solution facilitate the electrochemical process. On the other hand, deprotonation process of POT $(\mathrm{BP} \rightarrow \mathrm{PN}$ transition) leads to a more viscoelastic state of POT film (zone II in Fig. 4b).

Interestingly, $\mathrm{d} f_{r} / \mathrm{d} R_{m}$ allows $\mathrm{BP} \rightleftarrows \mathrm{PN}$ transitions to be investigated. At potentials further of $0.7 \mathrm{~V}$, hydrolysis of film can occur increasing the film porosity and film attenuation $[68,69]$. In other experimental methodologies, one can found difficulties to interpret the viscoelastic behaviour owing to the time to obtain the acoustic impedance spectra by a network analyser. Here, the high-speed acquisition of QCM-R can overcome this obstacle.

Zone III. $\mathrm{d} f_{r} / \mathrm{d} R_{m}$ in this zone shows a similar asymmetry between oxidation and reduction transitions. In the reduction direction, $\mathrm{d} f_{r} / \mathrm{d} R_{m}$ is practically constant around $+50 \mathrm{~Hz} \Omega^{-1}$ from $0.1 \mathrm{~V}$ to $-0.2 \mathrm{~V}$. The viscoelastic state of POT are kept constant despite free water insertion and anion expulsion by reduction of $\mathrm{P}$ centres to form the LE lattice. In the oxidation direction, $\mathrm{d} f_{r} / \mathrm{d} R_{m}$ is constant around $+30 \mathrm{~Hz} \Omega^{-1}$. However, we have some constraints to explain this difference because oxygen or hydrogen in solution could be involved in parasitic reactions affecting the viscoelasticity of film in this range of potential $[54,55]$

Inner reference potentials. POT also shows singular viscoelastic states at some specific potentials. These potentials can be used as inner reference potentials where POT shows specific characteristics in terms of structure, ion/free water population, film thickness and viscoelasticity. Two special circumstances are also found where $\Delta R_{m}$ or $\Delta f_{r}$ is constant.

In four punctual circumstances, $\mathrm{d} f_{r} / \mathrm{d} R_{m}$ is infinite (1-4 in Fig. $\left.4 \mathrm{~b}\right)$. POT shows this event at $0.147 \mathrm{~V}$ in the oxidation direction and at $0.66 \mathrm{~V}, 0.492 \mathrm{~V}$ and $0.297 \mathrm{~V}$ in the reduction direction. At these potentials, we can not be confident that POT is a very rigid material. However, we do consider these points as the stiffest states that POT can achieve 
because $\Delta R_{m}$ is constant [22]. Moreover, POT surface could be smooth avoiding the effect of trapped solvent over the motional resistance [20].

1) At $0.147 \mathrm{~V}$, the first coil structures formed by the strong interactions between $\mathrm{HSO}_{4}^{-}$and $\mathrm{P}$ centres involve repulsive interactions between $\mathrm{P}$ centres embedded in the LE lattice (Fig. S2). At this potential, the increase of film thickness starts.

2) At $0.660 \mathrm{~V}, \mathrm{BP}$ centres appear in the PN lattice involving attractive interactions between centres. $\mathrm{BP} \rightarrow \mathrm{P}$ transition does not occur. Moreover, POT film starts to recover water molecules expelled during oxidation.

3) At $0.492 \mathrm{~V}$, POT has a mixed P-BP lattice. At this potential, the maximum rate of change of $\Delta d_{f}^{\prime}$ takes place due to free water insertion from $\mathrm{BP} \rightarrow \mathrm{P}$ transition. Moreover, $\mathrm{PN} \rightarrow \mathrm{BP}$ transition is almost over and $\mathrm{P} \rightarrow \mathrm{LE}$ transition does not occur.

4) At $296 \mathrm{~V}, \mathrm{BP}$ centres disappears and P centres start to be reduced to LE centres. Then, $\Delta d_{f}^{\prime}$ decreases owing to $\mathrm{HSO}_{4}^{-}$expulsion despite free water insertion.

In Fig. $4 \mathrm{~b}$, the grey zone delimitates the region where $\mathrm{d} f_{r} / \mathrm{d} R_{m} \leq \pm 10 \mathrm{~Hz} \Omega^{-1}$. In some circumstance, $\mathrm{d} f_{r} / \mathrm{d} R_{m}$ shows lower values than $\pm 10 \mathrm{~Hz} \Omega^{-1}$ (5-8 in Fig. $4 \mathrm{~b}$ ). In all these points, $d f_{r} / d R_{m}$ changes between positive and negative values in narrow intervals of potentials less than $60 \mathrm{mV}$. Here, POT could be considered as a viscous material which softens the resonant wave of quartz. However, all results point to an acoustically thin polymer and $\mathrm{d} f_{r} / \mathrm{d} R_{m}$ has not constant values. That fact could take place at particular transitions between redox states of POT where $\mathrm{d} f_{r} / \mathrm{d} R_{m}$ changes between positive and negative values.

5) From $0 \mathrm{~V}$ to $0.06 \mathrm{~V}, \mathrm{LE} \rightarrow \mathrm{P}$ transition starts. The initial stage of POT oxidation under these experimental conditions only takes place by $\mathrm{HSO}_{4}^{-}$insertion and $\mathrm{H}_{2} \mathrm{O}$ expulsion [54]. Consequently, the thickness decrease is caused by an excess of $\mathrm{H}_{2} \mathrm{O}$ expulsion. Unfortunately, we can misinterpret the results because of the presence of parasitic reactions $[54,55]$.

6) Between $0.515 \mathrm{~V}$ and $0.550 \mathrm{~V}$ in the oxidation direction, $\mathrm{BP} \rightarrow \mathrm{PN}$ transition starts involving $\mathrm{H}_{3} \mathrm{O}^{+}$expulsion with a maximum rate changes of thickness. Moreover, $\mathrm{LE} \rightarrow \mathrm{P}$ has been finished.

7) From $0.7 \mathrm{~V}$ to $0.68 \mathrm{~V}$, the quick potential direction change could involve a severe structure perturbation caused by $\mathrm{H}_{2} \mathrm{O}$ and $\mathrm{H}_{3} \mathrm{O}^{+}$insertion during reduction of $\mathrm{PN}$ centres. 
8) Between $0.43 \mathrm{~V}$ to $0.415 \mathrm{~V}$, the maximum formation of polarons from BP centres in POT during the $\mathrm{BP} \rightarrow \mathrm{P}$ transition together with the end of $\mathrm{PN} \rightarrow \mathrm{BP}$ transition take place. In this point, the film reaches the maximum thickness.

\subsection{Scan rate}

In previous section, cyclic voltammetry was performed at $10 \mathrm{mV} \mathrm{s}^{-1}$. At low scan rates, fast and slow species participate during the electrochemical reactions of POT. On the contrary, we can hinder the transfer of slow species transfers increasing the voltammetric scan rate. In POT films, hydrated proton transfer was resolved as the slower specie [54]. This transfer could be limited by the hopping of protons between donor and acceptor amine groups similar to the Grotthuss mechanism.

In zone II of Fig. 4b, POT deprotonation involves stiffness loss of film up to a quasi-viscous state $\left(\mathrm{d} f_{r} / \mathrm{d} R_{m}\right.$ is $\left.-15 \mathrm{~Hz} \Omega^{-1}\right)$. Theoretically, we could avoid this state of POT increasing the scan rate of potential sweep. For practical application, the exclusive participation of anions would keep a good stiffness of film. However, the formation of stable interactions between participating species (POT, anions, cations and solvent) could be a determinant factor as scan rate increases.

Fig. 5a shows $\mathrm{d} f_{r} / \mathrm{d} R_{m}$ evolution during the oxidation transitions of POT film at different scan rates. We can explain the results if we consider that the formation of stable interactions inside POT decreases as scan rate increases making the film a less rigid material. Between $-0.2 \mathrm{~V}$ and $0.1 \mathrm{~V}, \mathrm{~d} f_{r} / \mathrm{d} R_{m}$ shows any tendency with scan rate. The potential where POT reaches the stiffest state is displaced at more anodic potentials as scan rate increases (about $0.150 \mathrm{~V}, 0.200 \mathrm{~V}$ and $0.260 \mathrm{~V}$ at 10,50 and $200 \mathrm{mV} \mathrm{s}^{-1}$, respectively). Thus, we need more time (or potential) to reach a certain amount of interaction/anions inside POT to reach this state. After that, the number of polarons increases stabilised by $\mathrm{HSO}_{4}^{-}$insertion to form coil structures and free water expulsion. This process involve an increase of POT stiffness at low scan rates. Around $0.450 \mathrm{~V}$, $\mathrm{d} f_{r} / \mathrm{d} R_{m}$ is $+135,+80$ and $+38 \mathrm{~Hz} \Omega^{-1}$ at 10,50 and $200 \mathrm{mV} \mathrm{s}^{-1}$, respectively). When the deprotonation process takes place, $\mathrm{d} f_{r} / \mathrm{d} R_{m}$ is close to $-15 \mathrm{~Hz} \Omega^{-1}$ at $10 \mathrm{mV} \mathrm{s}^{-1}$ and it is reduced to $-1 \mathrm{~Hz} \Omega^{-1}$ at $200 \mathrm{mV} \mathrm{s}^{-1}$ between $0.55 \mathrm{~V}$ and $0.7 \mathrm{~V}$.

During the reduction transitions, POT continues to show a more viscoelastic state at faster scan rates (Fig. 5b). As an examples, the protonation process around $0.6 \mathrm{~V}$ (the $\mathrm{PN} \rightarrow \mathrm{BP}$ transition) shows $\mathrm{d} f_{r} / \mathrm{d} R_{m}$ values close to $-40 \mathrm{~Hz} \Omega^{-1}$ at $10 \mathrm{mV} \mathrm{s}^{-1}$ whereas $\mathrm{d} f_{r} / \mathrm{d} R_{m}$ at faster scan rates is below $-10 \mathrm{~Hz} \Omega^{-1}$ indicating that POT film is viscous. On 
the other hand, POT film can reach its stiffest state at $0.25-0.3 \mathrm{~V}$ at slower scan rates between $\mathrm{BP} \rightarrow \mathrm{P}$ and $\mathrm{P} \rightarrow \mathrm{LE}$ transitions. However, $\mathrm{d} f_{r} / \mathrm{d} R_{m}$ reaches $+600 \mathrm{~Hz} \Omega^{-1}$ around $0.2 \mathrm{~V}$ at the fastest scan rate.

\subsection{Dopant anion}

The interaction between anions and POT can be different depending on the anion nature $[55,56]$. In this work, POT film was generated in $\mathrm{H}_{2} \mathrm{SO}_{4}$ solution and, then, cycled in three different free-monomer acid solutions $\left(0.5 \mathrm{M} \mathrm{HClO}_{4}, \mathrm{H}_{2} \mathrm{SO}_{4}\right.$ or $\left.\mathrm{HNO}_{3}\right)$. It is important to take into account that polymer structure is adapted to $\mathrm{HSO}_{4}^{-}$of electrosynthesis solution[56]. After few voltammetric cycles in the new solution, POT adopts immediately the identity of present anions. We expect that the molecular reconfiguration of the mobile polymer chains to be a determinant of film viscoelastic properties.

First, we analyse the oxidation half cycle. Fig. 6a shows the evolution of $\mathrm{d} f_{r} / \mathrm{d} R_{m}$ for a POT film immersed in three different acid solutions during the oxidation transitions. As can be seen, $\mathrm{d} f_{r} / \mathrm{d} R_{m}$ when $\mathrm{ClO}_{4}^{-}$is the anion inserted is higher than in other acid solution. This fact is especially relevant when the results in $\mathrm{HClO}_{4}$ and $\mathrm{H}_{2} \mathrm{SO}_{4}$ solution are compared. In this case, both anions in solution $\left(\mathrm{ClO}_{4}^{-}\right.$and $\left.\mathrm{HSO}_{4}^{-}\right)$have similar molecular weight (99.5 and $97 \mathrm{~g} \mathrm{~mol}^{-1}$, respectively), molecular volume (47 and $45 \AA^{3}$, respectively) and molecular geometry (tetrahedral). In spite of these physical similitudes, the insertion of $\mathrm{ClO}_{4}^{-}$involve an increases of POT stiffness during their insertion. Specially, $\mathrm{d} f_{r} / \mathrm{d} R_{m}$ is close to $-100 \mathrm{~Hz} \Omega^{-1}$ when $\mathrm{ClO}_{4}^{-}$is inserted in the film during the deprotonation process $\left(\mathrm{BP} \rightarrow \mathrm{PN}\right.$ transition) around $0.55 \mathrm{~V}$. In other solutions, $\mathrm{d} f_{r} / \mathrm{d} R_{m}$ is near or below the characteristic value of viscous materials.

The greater affinity of POT by $\mathrm{ClO}_{4}^{-}$could cause this behaviour $[69,70]$. Moreover, greater anions involve a greater degree of POT dehydration increasing POT stiffness owing to the exclusion effect [56]. It is also important to remember that this anion is more hydrophobic than $\mathrm{NO}_{3}^{-}$or $\mathrm{HSO}_{4}^{-}$following the Hofmeister series [71]. On the contrary, the insertion of a smaller anion or more hydrophilic involves weak interactions and less water expulsion allowing the POT film to reach a more viscoelastic state. A similar tendency was observed for PANI films [13].

In contrast, this tendency is inverted during the reduction half cycle (Fig. 6b). The expulsion of smaller anion $\left(\mathrm{NO}_{3}^{-}\right)$show greater $\mathrm{d} f_{r} / \mathrm{d} R_{m}$ values than the other anions. In fact, $\mathrm{ClO}_{4}^{-}$shows the lower $\mathrm{d} f_{r} / \mathrm{d} R_{m}$. It is expected that the insertion of greater anions 
leads to a more swollen POT films when it is completely oxidized [56]. In a thinner film as the formed after the insertion of $\mathrm{NO}_{3}^{-}$, the anions expulsed allows a fast formation of new interaction inside the film. This fact could involve a fast packing of POT making this film stiffer. On the contrary, the difficulty to extract $\mathrm{ClO}_{4}^{-}$during the voltammetric cycle slows the formation of new interaction making the film less rigid together with the insertion of a greater amount of free water molecule than in presence of $\mathrm{NO}_{3}^{-}$.

Finally, POT in $\mathrm{HClO}_{4}$ solution show the more rigid state from $0.1 \mathrm{~V}$ to $-0.1 \mathrm{~V}$ in Fig. 6b. In the complete reduction of POT, $\mathrm{ClO}_{4}^{-}$could be retained because a small number of anions could not exit from the packed polymer, then, the charge balance take place by insertion of $\mathrm{H}_{3} \mathrm{O}^{+}[56,72]$. This could be the cause of the stiffer state showed by POT in this potential range caused by permanently inserted $\mathrm{ClO}_{4}^{-}$.

\subsection{Relaxation}

In cyclic voltammetry, if POT films are reduced during a specific time, the oxidation peak of the first voltammetric cycle differs from the voltammetric cycle of the relaxed POT film (Fig. 7a). This phenomenon called "first cycle effect", "aging", "conformational relaxation" or "memory effect" has been extensively studied experimentally and theoretically [73-76]. Otero et al suggested that the oxidation process of a packed film consist in three consecutive steps [77]: electron loss, conformational relaxation, species exchange (ions, ion pairs or solvent). In this work, $-0.1 \mathrm{~V}$ was applied during $15 \mathrm{~s}$ after the voltammetric stabilization in three different free-monomer acid solutions $\left(0.5 \mathrm{M} \mathrm{HClO}_{4}, \mathrm{H}_{2} \mathrm{SO}_{4}\right.$ or $\left.\mathrm{HNO}_{3}\right)$. As it is observed in Fig. 7a, this time is enough to obtain a packed polymer. Longer polarization times cause more packed structures of polymer [78]. However, we tried to be cautious to not extend $15 \mathrm{~s}$ because parallel reaction observed around $-0.1 \mathrm{~V}$ could involve undesirable changes of POT films $[54,56]$.

Fig. 7b shows the evolution of $\mathrm{d} f_{r} / \mathrm{d} R_{m}$ for a POT film immersed in three different acid solutions during the first oxidation transitions after $15 \mathrm{~s}$ at $-0.1 \mathrm{~V}$. $\mathrm{In}_{2} \mathrm{SO}_{4}$ and $\mathrm{HNO}_{3}$ solutions, $\mathrm{d} f_{r} / \mathrm{d} R_{m}$ does not changes up to the current intensity increases. In this moment, anions can enter inside of unpacked film. On the contrary, $\mathrm{d} f_{r} / \mathrm{d} R_{m}$ in $\mathrm{HClO}_{4}$ does not show this behaviour. In this case, hydrated protons (smaller ions) can exit from packed film before the $\mathrm{ClO}_{4}^{-}$insertion. A similar profile is observed in voltammograms of Fig. 7a, current intensity is $0 \mathrm{~mA} \mathrm{~cm}^{-2}$ in $\mathrm{H}_{2} \mathrm{SO}_{4}$ and $\mathrm{HNO}_{3}$ solutions, whereas current intensity increase continuously in $\mathrm{HClO}_{4}$ from $-0.1 \mathrm{~V}$ and $0 \mathrm{~V}$. 
After that, $\mathrm{d} f_{r} / \mathrm{d} R_{m}$ is infinite at $0.05,0.06$ and $0.08 \mathrm{~V}$ in $\mathrm{H}_{2} \mathrm{SO}_{4}, \mathrm{HNO}_{3}$ and $\mathrm{HClO}_{4}$ solutions, respectively. These potentials match the onset potentials where current intensities increase in $\mathrm{H}_{2} \mathrm{SO}_{4}$ and $\mathrm{HNO}_{3}$ solutions. Therefore, we consider that at these potentials the anion insertion and coil structure formation begins. The formation of coil structures with strong repulsive interaction leads to increase the POT stiffness. This can be extrapolated to POT in $\mathrm{HClO}_{4}$ solution. In this case, we need to apply more potentials $(0.08 \mathrm{~V})$ to reach a more open structure to insert $\mathrm{ClO}_{4}^{-}$and the consequent phenomena (coil structures and interactions)

Now, we can compare the viscoelastic state between a relaxed (Fig. 6a) or packed film (Fig. 7b) during the $\mathrm{LE} \rightarrow \mathrm{P}$ transition. Firstly, we consider that in a packed film the amount of inserted water molecules or ionic pairs is less than in a relaxed film. A priori, packed POT has to be stiffener than relaxed POT. However, the relaxation is a more complex process. In general, $\mathrm{d} f_{r} / \mathrm{d} R_{m}$ values for a packed film are lower than a relaxed film. This result means that the electrochemical relaxation of POT involves the formation of a film more viscoelastic than a relaxed film. POT unpacking together with the insertion of anions, solvent or ion pairs should involve a strong structure perturbation of film. On the contrary, transfer of species and formation of interactions do not result a traumatic structural conformation like in the relaxation process.

\section{CONCLUSION}

Instantaneous resonant frequency/motional resistance ratio $\left(\mathrm{d} f_{r} / \mathrm{d} R_{m}\right)$ during the electrochemical process provides a relevant information on the changes of viscoelastic states in POT films. In spite of we can not explain the complete viscoelastic evolution of acoustically thin POT films during electrochemical reactions, we demonstrate several conclusions from $\mathrm{d} f_{r} / \mathrm{d} R_{m}$ results.

In general, the anion-polymer interactions during the $\mathrm{LE} \rightleftarrows \mathrm{P} \rightleftarrows \mathrm{BP}$ transitions yield more rigid films than that during the protonation/deprotonation processes of $\mathrm{BP} \rightleftarrows \mathrm{PN}$ transitions. However, the viscoelastic variations of POT films have a clear asymmetry between the oxidation and the reduction processes where the reduction processes takes place on a slightly stiffer polymer than the oxidation processes. The reduction of stable interactions (fast scan rates), the relaxation of film and smaller anions involve the formation of more viscoelastic POT films. On the contrary, we can increase the stiffness of film at slower potential perturbation to form more stable interactions and structures, 
reaching a relaxed film without dramatic structure reconfigurations or using anions with a great affinity with the film.

As an external applied potential can control these features, the understanding of mechanical properties in this type of polymers is essential for the creation of electronic devices like artificial muscles, (bio)sensors or electrochemical capacitors. This analysis opens new possibilities to study the viscoelastic states of different conducting polymers during their electrochemical transitions. Moreover, $\mathrm{d} f_{r} / \mathrm{d} R_{m}$ could be used as a prelaminar information to posteriorly complete the analysis of BVD circuits provided by a network analyser which provide a more realistic information of viscoelastic properties of films.

\section{ACKNOWLEDGMENTS}

Part of this work was supported by FEDER-CICyT project CTQ2011-28973/BQU

\section{REFERENCES}

[1] G. Inzelt, Mechanism of Charge Transport in Polymer Modified Electrodes, in: Bard, A. J. (Ed.), Electroanalytical Chemistry, A Series of Advances, Marcel Dekker, Inc., New York, 1993: pp. 89-241.

[2] M.E.G. Lyons, Electroactive Polymer Electrochemistry, Part 1: Fundamentals, 1st ed., Springer, New York, 1995.

[3] M.E.G. Lyons, Electroactive Polymer Electrochemistry: Part 2: Methods and Applications, Springer, 1996.

[4] G. Inzelt, M. Pineri, J.W. Schultze, M.A. Vorotyntsev, Electron and proton conducting polymers: recent developments and prospects, Electrochim. Acta. 45 (2000) 2403-2421.

[5] K. Kaneto, M. Kaneko, Contribution of conformational change of polymer structure to electrochemomechanical deformation based on polyaniline, Appl. Biochem. Biotechnol. 96 (2001) 13-23.

[6] L. Lizarraga, E.M. Andrade, M.I. Florit, F.V. Molina, Quasi-Equilibrium Volume Changes of Polyaniline Films upon Redox Switching. Formal Potential Distribution and Configurational Modeling, J. Phys. Chem. B. 109 (2005) 1881518821.

[7] L.T.T. Kim, C. Gabrielli, A. Pailleret, H. Perrot, Correlation between ionexchange properties and swelling/shrinking processes in hexasulfonated calix[6]arene doped polypyrrole films: ac-electrogravimetry and electrochemical atomic force microscopy investigations, Electrochim. Acta. 56 (2011) 3516-3525.

[8] Y. Lee, C. Chang, S. Yau, L. Fan, Y. Yang, L.O. Yang, et al., Conformations of Polyaniline Molecules Adsorbed on Au(111) Probed by in Situ STM and ex Situ XPS and NEXAFS, J. Am. Chem. Soc. 131 (2009) 6468-6474.

[9] A. Fernandez-Barbero, I.J. Suarez, B. Sierra-Martin, A. Fernandez-Nieves, F. Javier de las Nieves, M. Marquez, et al., Gels and microgels for nanotechnological applications, Adv. Colloid Interface Sci. 147-48 (2009) 88-108.

[10] A.R. Hillman, M.A. Mohamoud, I. Efimov, Time-Temperature Superposition and the Controlling Role of Solvation in the Viscoelastic Properties of Polyaniline Thin Films, Anal. Chem. 83 (2011) 5696-5707.

[11] T.F. Otero, Biomimetic Conducting Polymers: Synthesis, Materials, Properties, 
Functions, and Devices, Polym. Rev. 53 (2013) 311-351.

[12] I. Jureviciute, S. Bruckenstein, A.R. Hillman, A. Jackson, Kinetics of redox switching of electroactive polymers using the electrochemical quartz crystal microbalance. Part I. Identifying the rate limiting step in the presence of coupled electron/ion and solvent transfer, Phys. Chem. Chem. Phys. 2 (2000) 4193-4198.

[13] M.A. Mohamoud, A.R. Hillman, The effect of anion identity on the viscoelastic properties of polyaniline films during electrochemical film deposition and redox cycling, Electrochim. Acta. 53 (2007) 1206-1216.

[14] R. Borjas, D. Buttry, Solvent Swelling Influences the Electrochemical-Behavior and Stability, J. Electroanal. Chem. 280 (1990) 73-90.

[15] J. Alder, J. Mccallum, Piezoelectric-Crystals for Mass and Chemical Measurements - a Review, Analyst. 108 (1983) 1169-1189.

[16] K.D. Pavey, Quartz crystal analytical sensors: the future of label-free, real-time diagnostics?, Expert Review of Molecular Diagnostics. 2 (2002).

[17] B. Wyszynski, T. Nakamoto, Linking Biological and Artificial Olfaction:

Biomimetic Quartz Crystal Microbalance Odor Sensors, IEEJ Trans. Electr. Electron. Eng. 4 (2009) 334-338.

[18] V. Granstaff, S. Martin, Characterization of a Thickness-Shear Mode Quartz Resonator with Multiple Nonpiezoelectric Layers, J. Appl. Phys. 75 (1994) 1319-1329.

[19] H.L. Bandey, A.R. Hillman, M.J. Brown, S.J. Martin, Viscoelastic characterization of electroactive polymer films at the electrode/solution interface, Faraday Discuss. 107 (1997) 105-121.

[20] A. Arnau, Y. Jimenez, R. Fernández, R. Torres, M. Otero, E.J. Calvo, Viscoelastic Characterization of Electrochemically Prepared Conducting Polymer Films by Impedance Analysis at Quartz Crystal Study of the Surface Roughness Effect on the Effective Values of the Viscoelastic Properties of the Coating, J. Electrochem. Soc. 153 (2006) C455-C466.

[21] M.A. Mohamoud, A.R. Hillman, I. Efimov, Film mechanical resonance phenomenon during electrochemical deposition of polyaniline, Electrochim. Acta. 53 (2008) 6235-6243.

[22] L.P. Bauermann, P.N. Bartlett, EQCM measurements of the ion and solvent flux in thin poly(aniline)-poly(styrenesulfonate) films during redox switching, Electrochimica Acta. 50 (2005) 1537-1546.

[23] G. Sauerbrey, The use of oscillators for weighing thin layers and for microweighing, Z. Physik. 155 (1959) 206-222.

[24] R.A. Etchenique, E.J. Calvo, Gravimetric measurement in redox polymer electrodes with the EQCM beyond the Sauerbrey limit, Electrochem. Commun. 1 (1999) 167-170.

[25] N. Oyama, T. Ohsaka, Coupling between electron and mass transfer kinetics in electroactive polymer films - An application of the in situ quartz crystal electrode, Progress in Polymer Science. 20 (1995) 761-818.

[26] D. Johannsmann, Viscoelastic analysis of organic thin films on quartz resonators, Macromol. Chem. Phys. 200 (1999) 501-516. doi:10.1002/(SICI)15213935(19990301)200:3<501::AID-MACP501>3.0.CO;2-W.

[27] D. Buttry, M. Ward, Measurement of Interfacial Processes at Electrode Surfaces with the Electrochemical Quartz Crystal Microbalance, Chem. Rev. 92 (1992) 13551379 .

[28] A.R. Hillman, Mobile species populations and viscoelastic effects in electroactive polymer films, Solid State Ionics. 94 (1997) 151-160.

[29] D. Gimenez-Romero, J. Agrisuelas, J.J. Garcia-Jareño, J. Gregori, C. Gabrielli, 
H. Perrot, et al., Electromechanical phase transition in hexacyanometallate nanostructure (Prussian blue), J. Am. Chem. Soc. 129 (2007) 7121-7126.

[30] M.A. Cooper, V.T. Singleton, A survey of the 2001 to 2005 quartz crystal microbalance biosensor literature: applications of acoustic physics to the analysis of biomolecular interactions, J. Mol. Recognit. 20 (2007) 154-184.

[31] R. Etchenique, V.L. Brudny, Characterization of porous polyanilinepolystyrenesulfonate composite films using EQCM, Electrochem. Commun. 1 (1999) 441-444.

[32] C. Gabrielli, A.A.O. Magalhaes, I.C.P. Margarit, H. Perrot, B. Tribollet, Study of chromate-zinc conversion process through microbalance/electroacoustic impedance coupling measurements, Electrochem. Commun. 6 (2004) 492-498.

[33] F. Xie, Z. Huang, C. Chen, Q. Xie, Y. Huang, C. Qin, et al., Preparation of Aufilm electrodes in glucose-containing Au-electroplating aqueous bath for highperformance nonenzymatic glucose sensor and glucose/O-2 fuel cell, Electrochem. Commun. 18 (2012) 108-111.

[34] P. Pieta, E. Grodzka, K. Winkler, M. Warczak, A. Sadkowski, G.Z. Zukowska, et al., Conductive, Capacitive, and Viscoelastic Properties of a New Composite of the C-60-Pd Conducting Polymer and Single-Wall Carbon Nanotubes, J. Phys. Chem. B. 113 (2009) 6682-6691.

[35] M.J. Brown, A.R. Hillman, S.J. Martin, R.W. Cernosek, H.L. Bandey, Manipulation of electroactive polymer film viscoelasticity: the roles of applied potential and frequency, J. Mater. Chem. 10 (2000) 115-126.

[36] L.E. Bailey, D. Kambhampati, K.K. Kanazawa, W. Knoll, C.W. Frank, Using surface plasmon resonance and the quartz crystal microbalance to monitor in situ the interfacial behavior of thin organic films, Langmuir. 18 (2002) 479-489.

[37] J.M. Kim, S.M. Chang, H. Muramatsu, In situ optoelectrochemical approach for the dynamic property study of polypyrrole thin film by quartz crystal combined with UV-visible advanced design, J. Electrochem. Soc. 146 (1999) 4544-4550.

[38] M. Skompska, A. Jackson, A.R. Hillman, Evolution from gravimetric to viscoelastic response of poly(3-methylthiophene)-loaded acoustic wave resonators, Phys. Chem. Chem. Phys. 2 (2000) 4748-4757.

[39] M.A. Mohamoud, A.R. Hillman, Viscoelastic phenomena during electrochemical deposition of polyaniline films, J. Solid State Electrochem. 11 (2007) 1043-1050.

[40] J.J. Garcia-Jareño, C. Gabrielli, H. Perrot, Validation of the mass response of a quartz crystal microbalance coated with Prussian Blue film for ac electrogravimetry, Electrochem. Commun. 2 (2000) 195-200.

[41] A.R. Hillman, A. Jackson, S.J. Martin, The Problem of Uniqueness of Fit for Viscoelastic Films on Thickness-Shear Mode Resonator Surfaces, Analytical Chemistry. 73 (2001) 540-549.

[42] S. Martin, V. Granstaff, G. Frye, Characterization of a Quartz Crystal Microbalance with Simultaneous Mass and Liquid Loading, Anal. Chem. 63 (1991) 2272-2281.

[43] M. Rodahl, F. Hook, B. Kasemo, QCM operation in liquids: An explanation of measured variations in frequency and Q factor with liquid conductivity, Anal. Chem. 68 (1996) 2219-2227.

[44] S.W. Lee, W.D. Hinsberg, Determination of the viscoelastic properties of polymer films using a compensated phase-locked oscillator circuit, Anal. Chem. 74 (2002) 125-131.

[45] J. Agrisuelas, C. Delgado, C. Gabrielli, J.J. Garcia-Jareño, H. Perrot, F. Vicente, 
Electrochemical stabilization of Prussian Blue films in $\mathrm{NH} 4 \mathrm{Cl}$ aqueous medium, ECS Transactions. 35 (2011) 53-61.

[46] A. Bund, M. Schneider, Characterization of the viscoelasticity and the surface roughness of electrochemically prepared conducting polymer films by impedance measurements at quartz crystals, J. Electrochem. Soc. 149 (2002) E331-E339.

[47] H. Muramatsu, A. Egawa, T. Ataka, Reliability of Correlation Between Mass Change and Resonant-Frequency Change for a Viscoelastic-Film-Coated QuartzCrystal, J. Electroanal. Chem. 388 (1995) 89-92.

[48] C.Y. Deng, M.R. Li, Q.J. Xie, M.L. Liu, Y.M. Tan, X.H. Xu, et al., New glucose biosensor based on a poly(o-phenylendiamine)/glucose oxidase-glutaraldehyde/Prussian blue/Au electrode with QCM monitoring of various electrode-surface modifications, Anal. Chim. Acta. 557 (2006) 85-94.

[49] R. Lucklum, C. Behling, P. Hauptmann, Role of mass accumulation and viscoelastic film properties for the response of acoustic-wave based chemical sensors, Anal. Chem. 71 (1999) 2488-2496.

[50] R. Lucklum, P. Hauptmann, The Delta f-Delta R QCM technique: an approach to an advanced sensor signal interpretation, Electrochim. Acta. 45 (2000) 3907-3916.

[51] J.M. Kim, S.M. Chang, H. Muramatsu, Monitoring changes in the viscoelastic properties of thin polymer films by the quartz crystal resonator, Polymer. 40 (1999) 3291-3299.

[52] C. Sousa, C. Compere, C. Dreanno, M.-P. Crassous, F. Gas, B. Baus, et al., Direct and fast detection of Alexandrium minutum algae by using high frequency microbalance, J. Microbiol. Methods. 104 (2014) 49-54.

[53] J. Agrisuelas, C. Gabrielli, J.J. García-Jareño, H. Perrot, F. Vicente, Kinetic and Mechanistic Aspects of a Poly(o-toluidine)-Modified Gold Electrode. 1. Simultaneous Cyclic Spectroelectrochemistry and Electrogravimetry Studies in H2SO4 Solutions, J. Phys. Chem. C. 116 (2012) 15620-15629.

[54] J. Agrisuelas, C. Gabrielli, J.J. García-Jareño, H. Perrot, F. Vicente, Kinetic and Mechanistic Aspects of a Poly(o-Toluidine)-Modified Gold Electrode. 2. Alternating Current Electrogravimetry Study in H2SO4 Solutions, J. Phys. Chem. C. 116 (2012) $15630-15640$.

[55] J. Agrisuelas, C. Gabrielli, J.J. Garcia-Jareño, H. Perrot, F. Vicente, Effects of anions size on the redox behavior of poly(o-toluidine) in acid solutions. An in situ visNIR cyclic spectroelectrogravimetry study, Electrochim. Acta. 125 (2014) 83-93.

[56] J. Agrisuelas, C. Gabrielli, J.J. García-Jareño, H. Perrot, F. Vicente, Effects of anion size on the electrochemical behavior of $\mathrm{H} 2 \mathrm{SO} 4$-structured poly(o-toluidine) films. An ac-electrogravimetry study in acid solutions, Electrochim. Acta. 132 (2014) 561573.

[57] J. Agrisuelas, C. Gabrielli, J.J. García-Jareño, H. Perrot, O. Sel, F. Vicente, Polymer dynamics in thin p-type conducting films investigated by ac-electrogravimetry. Kinetics aspects on anion exclusion, free solvent transfer, and conformational changes in poly(o-toluidine), Electrochimica Acta. 153 (2015) 33-43.

doi:10.1016/j.electacta.2014.11.159.

[58] Q. Yang, Y. Zhang, H. Li, Y. Zhang, M. Liu, J. Luo, et al., Electrochemical copolymerization study of o-toluidine and o-aminophenol by the simultaneous EQCM and in situ FTIR spectroelectrochemistry, Talanta. 81 (2010) 664-672.

[59] V. Bavastrello, S. Carrara, M.K. Ram, C. Nicolini, Optical and Electrochemical Properties of Poly(o-toluidine) Multiwalled Carbon Nanotubes Composite Langmuir-Schaefer Films, Langmuir. 20 (2004) 969-973.

[60] Y.Z. Wang, J. Joo, C.-H. Hsu, J.P. Pouget, A.J. Epstein, Charge Transport of 
Hydrochloric Acid Doped Polyaniline and Poly(o-toluidine) Fibers: Role of Processing, Macromolecules. 27 (1994) 5871-5876.

[61] P. Ocon, L. Vazquez, R.C. Salvarezza, A.J. Arvia, P. Herrasti, J.M. Vara, Scanning Tunneling Microscopy Fractal Characterization of Poly(o-toluidine) Films Produced Electrochemically on Polyfaceted Gold Single Crystal Spheres, J. Phys. Chem. 98 (1994) 2418-2425.

[62] J.A. Osaheni, S.A. Jenekhe, H. Vanherzeele, J.S. Meth, Third-order nonlinear optical properties of thin films of polyanilines and poly(o-toluidines), Chem. Mater. 3 (1991) 218-221.

[63] S. Bilal, A.-H.A. Shah, R. Holze, A correlation of electrochemical and spectroelectrochemical properties of poly(o-toluidine), Electrochim. Acta. 54 (2009) 4851-4856.

[64] M. Jozefowicz, A. Epstein, J. Pouget, J. Masters, A. Ray, A. Macdiarmid, X-Ray Structure of the Polyaniline Derivative Poly(ortho-Toluidine) - the Structural Origin of Charge Localization, Macromolecules. 24 (1991) 5863-5866.

[65] J. Agrisuelas, C. Gabrielli, J.J. García-Jareño, H. Perrot, O. Sel, F. Vicente, Polymer dynamics in thin p-type conducting films investigated by ac-electrogravimetry. Kinetics aspects on anion exclusion, free solvent transfer, and conformational changes in poly(o-toluidine), Electrochimica Acta. 153 (2015) 33-43.

[66] A. Elmansouri, A. Outzourhit, A. Lachkar, N. Hadik, A. Abouelaoualim, M.E. Achour, et al., Influence of the counter ion on the properties of poly(o-toluidine) thin films and their Schottky diodes, Synth. Met. 159 (2009) 292-297.

[67] M.J.R. Presa, D. Posadas, M.I. Florit, Voltammetric study of the reduction and relaxation of poly(o-toluidine). Effect of the polymer thickness and the external electrolyte nature and concentration, J. Electroanal. Chem. 482 (2000) 117-124.

[68] J. Lopez-Palacios, E. Munoz, M. Aranzazu Heras, A. Colina, V. Ruiz, Study of polyaniline films degradation by thin-layer bidimensional spectroelectrochemistry, Electrochim. Acta. 52 (2006) 234-239.

[69] X. Yang, Q. Xie, S. Yao, A comparative study on polyaniline degradation by an electrochemical quartz crystal impedance system: electrode and solution effects, Synth. Met. 143 (2004) 119-128.

[70] M.C. Gupta, S.S. Umare, Studies on poly(o-methoxyaniline), Macromolecules. 25 (1992) 138-142.

[71] Y. Zhang, P.S. Cremer, Interactions between macromolecules and ions: the Hofmeister series, Curr. Opin. Chem. Biol. 10 (2006) 658-663.

[72] M.J. Henderson, A. Robert Hillman, E. Vieil, A combined electrochemical quartz crystal microbalance (EQCM) and probe beam deflection (PBD) study of a poly(o-toluidine) modified electrode in perchloric acid solution, J. Electroanal. Chem. 454 (1998) 1-8.

[73] A. Malinauskas, Slow relaxation of conducting polymers: Differences between ring- and N-substituted polyanilines, Ber. Bunsen-Ges. Phys. Chem. Chem. Phys. 102 (1998) 972-973.

[74] W.A. Marmisolle, D. Posadas, M.I. Florit, Electrochemical aging of poly(aniline) and its ring substituted derivatives, J. Phys. Chem. B. 112 (2008) 1080010805.

[75] T.F. Otero, H. Grande, J. Rodriguez, Conformational relaxation during polypyrrole oxidation: From experiment to theory, Electrochimica Acta. 41 (1996) 1863-1869. doi:10.1016/0013-4686(96)86826-5.

[76] M.J.R. Presa, H.L. Bandey, R.I. Tucceri, M.I. Florit, D. Posadas, A.R. Hillman, Charge transfer in poly(o-toluidine) gold modified electrodes. An EIS study of the 
reduced state, J. Electroanal. Chem. 455 (1998) 49-55.

[77] T.F. Otero, H.J. Grande, J. Rodriguez, Reinterpretation of polypyrrole electrochemistry after consideration of conformational relaxation processes, J. Phys.

Chem. B. 101 (1997) 3688-3697. doi:10.1021/jp9630277.

[78] T.F. Otero, J.G. Martinez, Structural and Biomimetic Chemical Kinetics: Kinetic Magnitudes Include Structural Information, Adv. Funct. Mater. 23 (2013) 404-416. 


\section{FIGURES LEGENDS}

Fig. 1. Representative cyclic voltammograms $\left(1^{\text {st }}, 50^{\text {th }}\right.$ and $100^{\text {th }}$ cycle $)$ during POT electrosynthesis in $0.5 \mathrm{M} \mathrm{H}_{2} \mathrm{SO}_{4}$ and $0.2 \mathrm{M}$ o-toluidine aqueous solution at $100 \mathrm{mV} \mathrm{s}^{-1}$ scan rate. Film thickness is approximately $350 \mathrm{~nm}$ considering the o-toluidine density $\left(1.01 \mathrm{~g} \mathrm{~cm}^{-3}\right)$ and mass deposited $\left(35 \mu \mathrm{g} \mathrm{cm}^{-2}\right)$.

Fig. 2. Resonant frequency, $\Delta f_{r}$, and motional resistance, $\Delta R_{m}$, for POT electrosynthesis in $0.5 \mathrm{M} \mathrm{H}_{2} \mathrm{SO}_{4}$ and $0.2 \mathrm{M}$ o-toluidine aqueous solution at $100 \mathrm{mV} \mathrm{s}^{-1}$ scan rate. The arrows show the direction of POT electrosynthesis. Solid lines (A, B and C) are simulated guide-to-the eye lines. Lines $\mathrm{A}$ and $\mathrm{C}$ are drawn with different slopes using information from Refs. [29,42]. The inset is a detailed evolution of $\Delta f_{r}$ and $\Delta R_{m}$ during voltammetric cycles around $70^{\text {th }}$ cycle.

Fig. 3. Stable voltammetric response of a POT film in $0.5 \mathrm{M} \mathrm{H}_{2} \mathrm{SO}_{4}$ aqueous solution $(\mathrm{pH} \approx 0.45)$ at $10 \mathrm{mV} \mathrm{s}^{-1}$ scan rate between $-0.2 \mathrm{~V}$ and $0.7 \mathrm{~V}$.

Fig. 4. Evolution of $\Delta f_{r}, \Delta R_{m}$ (a) and $\mathrm{d} f_{r} / \mathrm{d} R_{m}$ (b) of a POT film in $0.5 \mathrm{M} \mathrm{H}_{2} \mathrm{SO}_{4}$ aqueous solution $(\mathrm{pH} \approx 0.45)$ at $10 \mathrm{mV} \mathrm{s}^{-1}$ scan rate between $-0.2 \mathrm{~V}$ and $0.7 \mathrm{~V}$. Open symbols indicate oxidation direction and closed symbols indicate reduction direction.

Fig. 5. Evolution of $\mathrm{d} f_{r} / \mathrm{d} R_{m}$ during the oxidation (a) and reduction (b) in the $9^{\text {th }}$ cycle of a relaxed POT film in $0.5 \mathrm{M} \mathrm{H}_{2} \mathrm{SO}_{4}$ aqueous solution $(\mathrm{pH} \approx 0.45)$ at $10 \mathrm{mV} \mathrm{s}^{-1}$ (squares), $50 \mathrm{mV} \mathrm{s}^{-1}$ (circles) and $200 \mathrm{mV} \mathrm{s}^{-1}$ (triangles).

Fig. 6. Evolution of $\mathrm{d} f_{r} / \mathrm{d} R_{m}$ during the oxidation (a) and reduction (b) in the $9^{\text {th }}$ cycle of a relaxed POT film in $0.5 \mathrm{M} \mathrm{H}_{2} \mathrm{SO}_{4}$ (squares), $0.5 \mathrm{M} \mathrm{HNO}_{3}$ (circles) and $0.5 \mathrm{M} \mathrm{HClO}_{4}$ (triangles) aqueous solution $(\mathrm{pH} \approx 0.45)$ at $100 \mathrm{mV} \mathrm{s}^{-1}$.

Fig. 7. $1^{\text {st }}$ and $9^{\text {th }}$ half oxidation cycle (a) and evolution of $\mathrm{d} f_{r} / \mathrm{d} R_{m}$ during the $1^{\text {st }}$ half oxidation cycle (b) of a POT film in $0.5 \mathrm{M} \mathrm{H}_{2} \mathrm{SO}_{4}$ (squares), $0.5 \mathrm{M} \mathrm{HNO}_{3}$ (circles) and $0.5 \mathrm{M} \mathrm{HClO}_{4}$ (triangles) aqueous solution $(\mathrm{pH} \approx 0.45)$ at $100 \mathrm{mV} \mathrm{s}^{-1}$. The initial potential was $-0.1 \mathrm{~V}$ applied during $15 \mathrm{~s}$. 
FIGURES

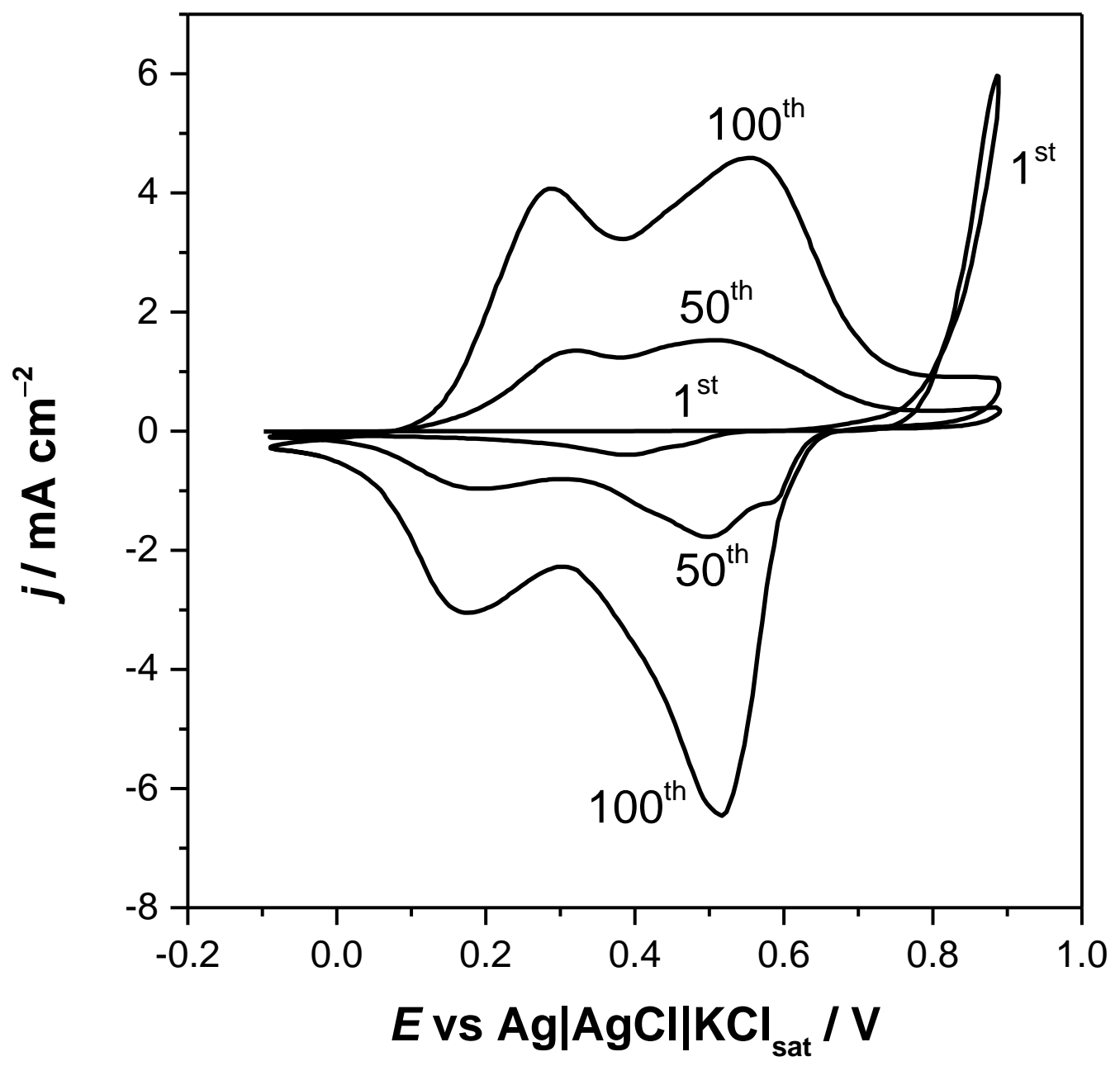

Fig. 1 


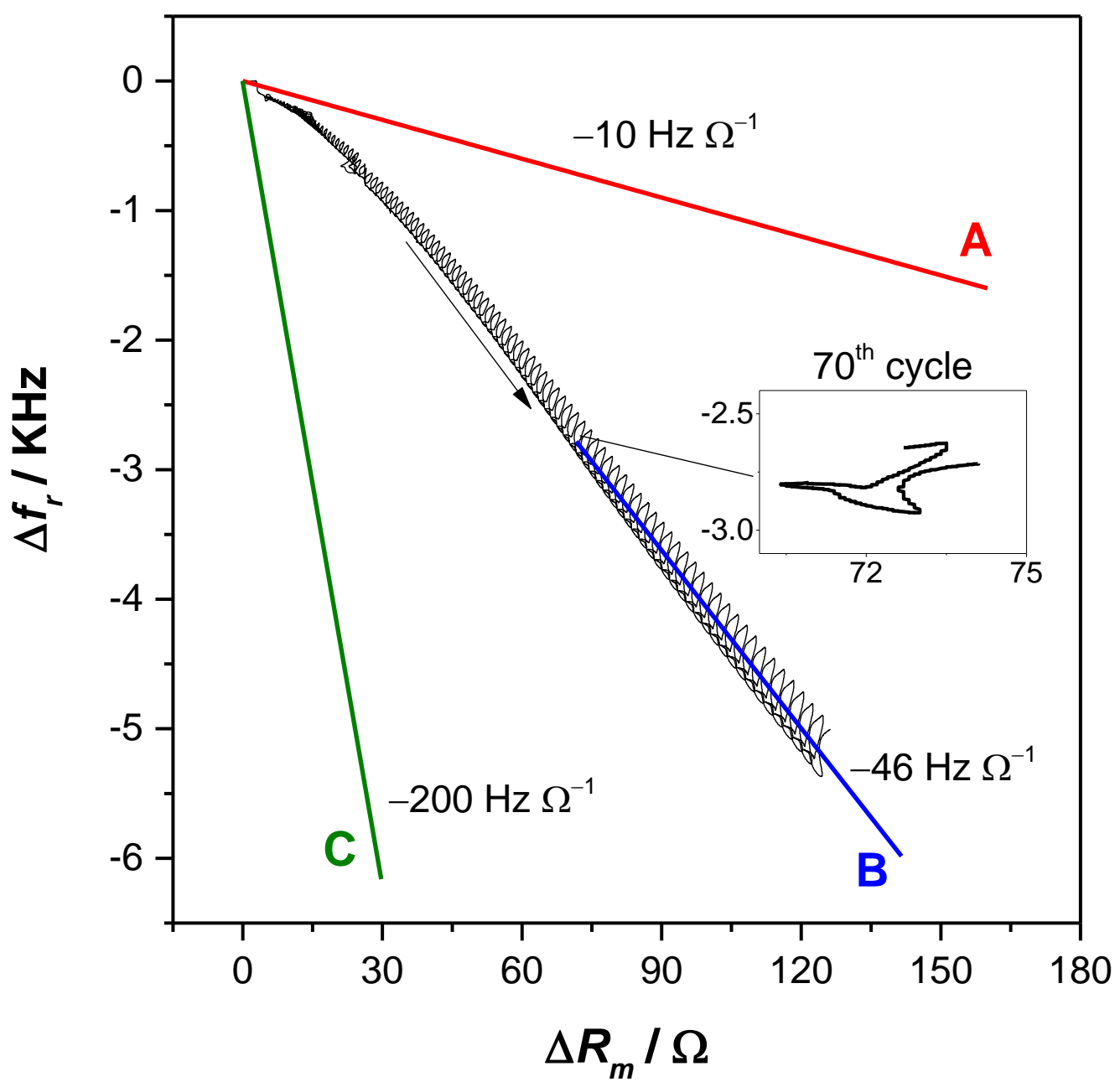

Fig. 2 


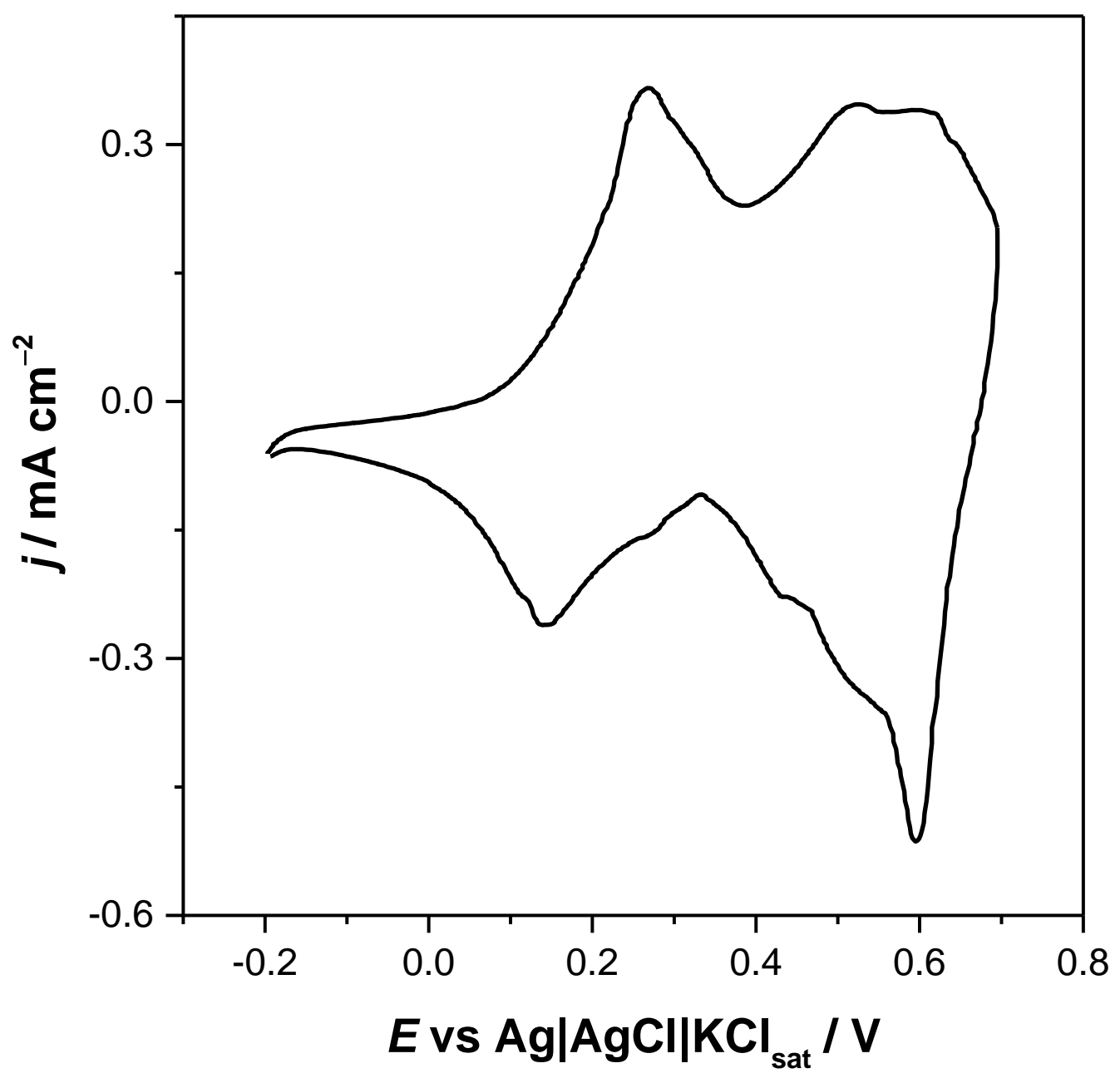

Fig. 3 


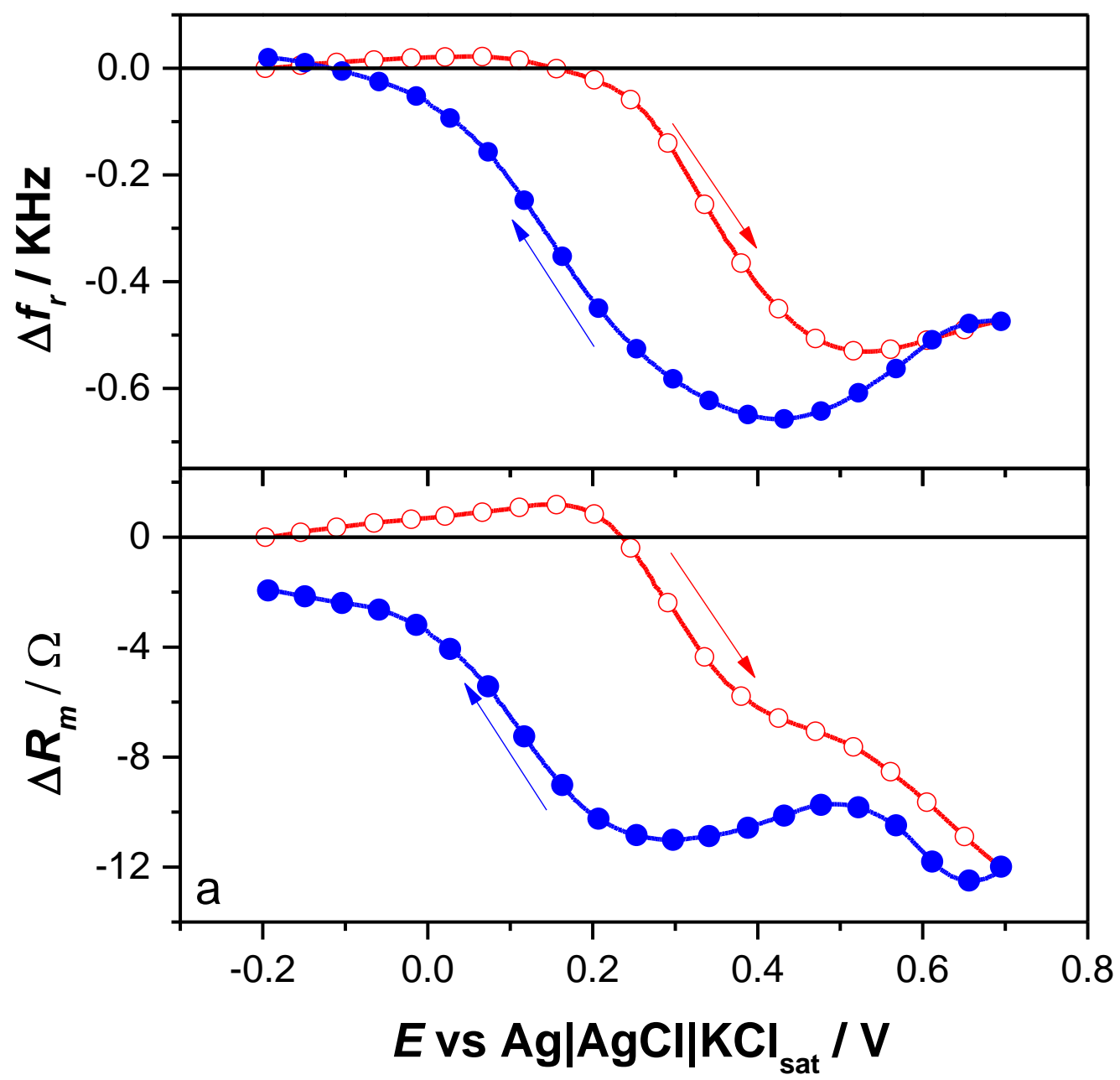

Fig. 4a 


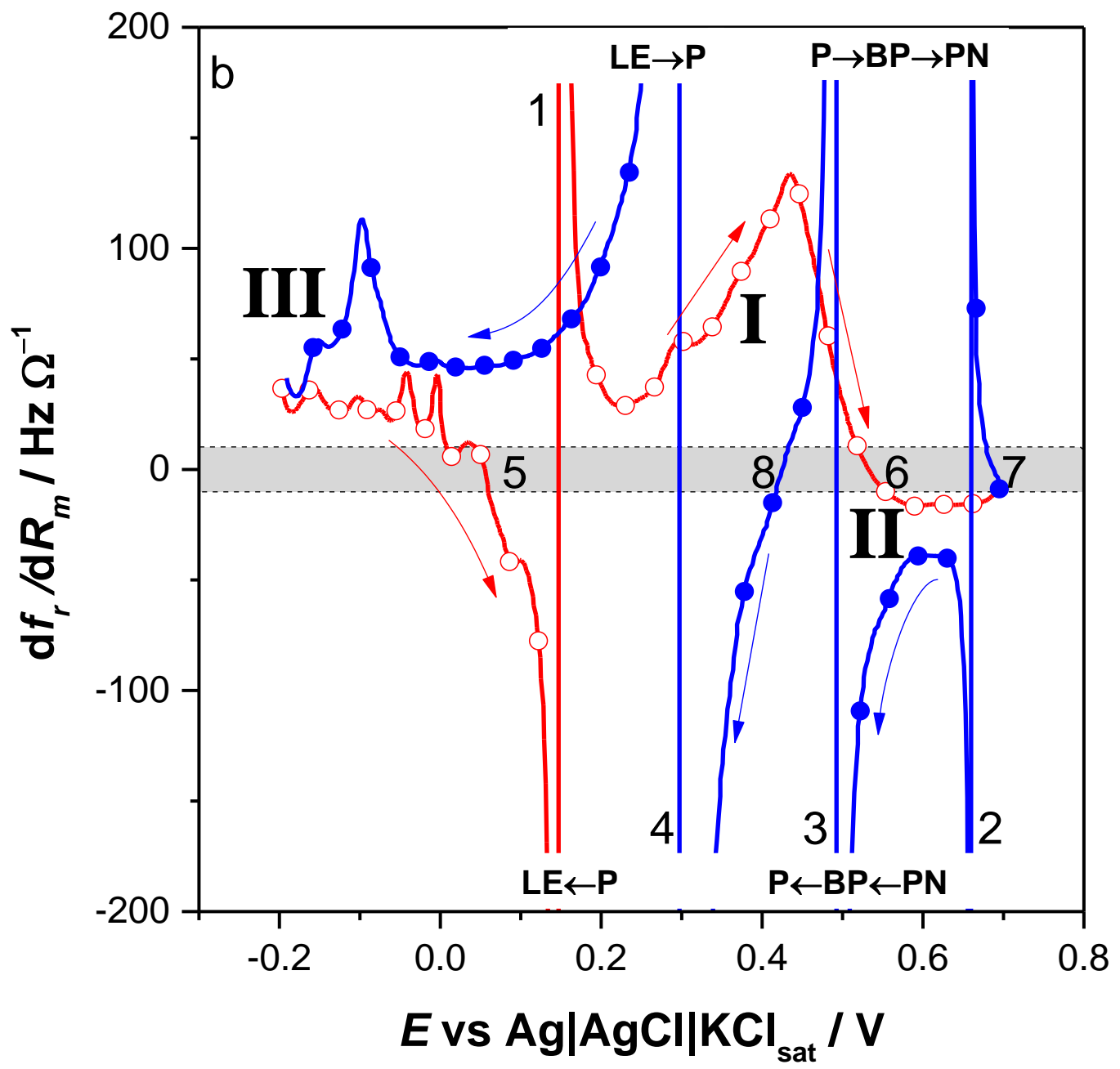

Fig. 4b 


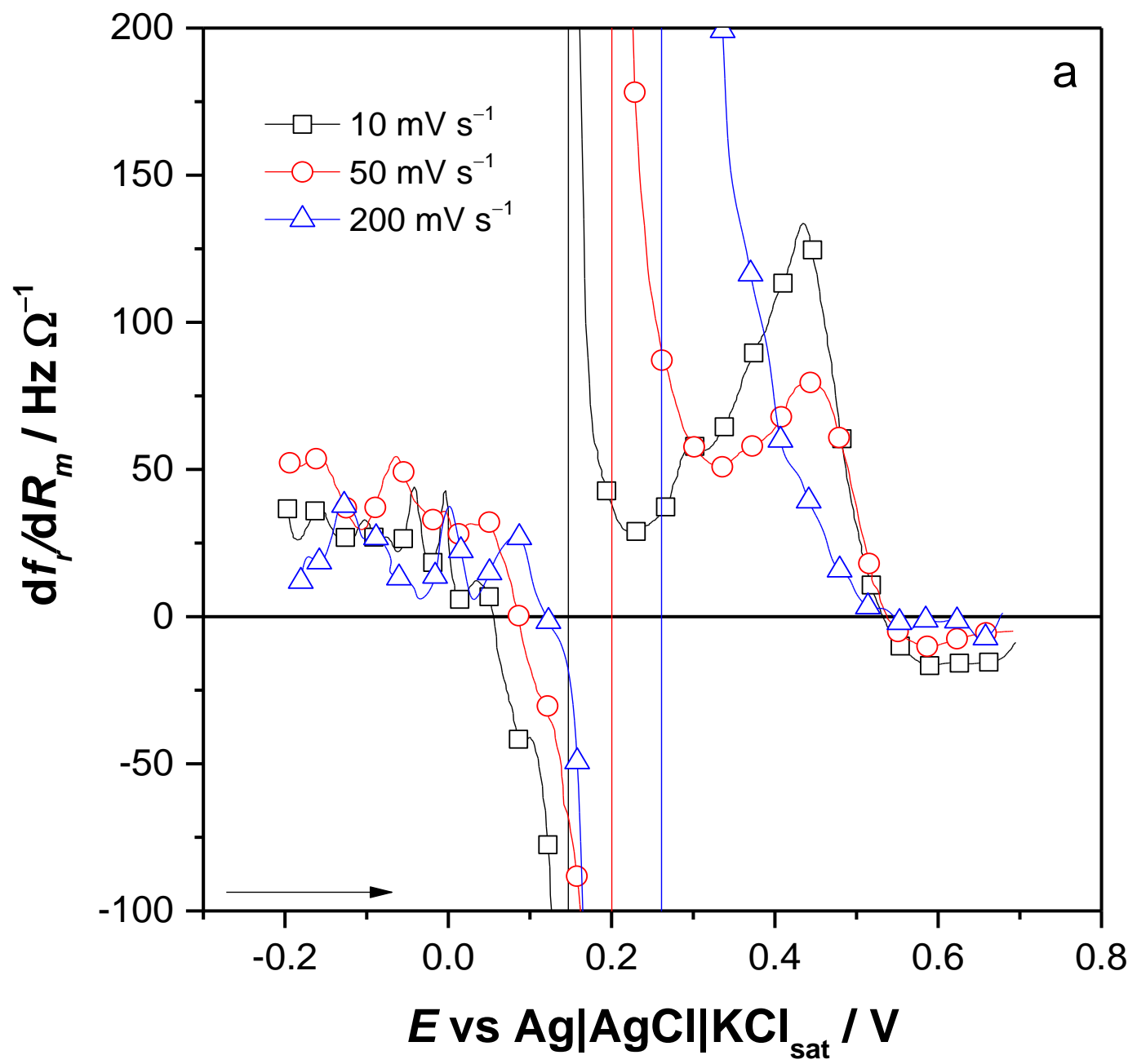

Fig. 5a 


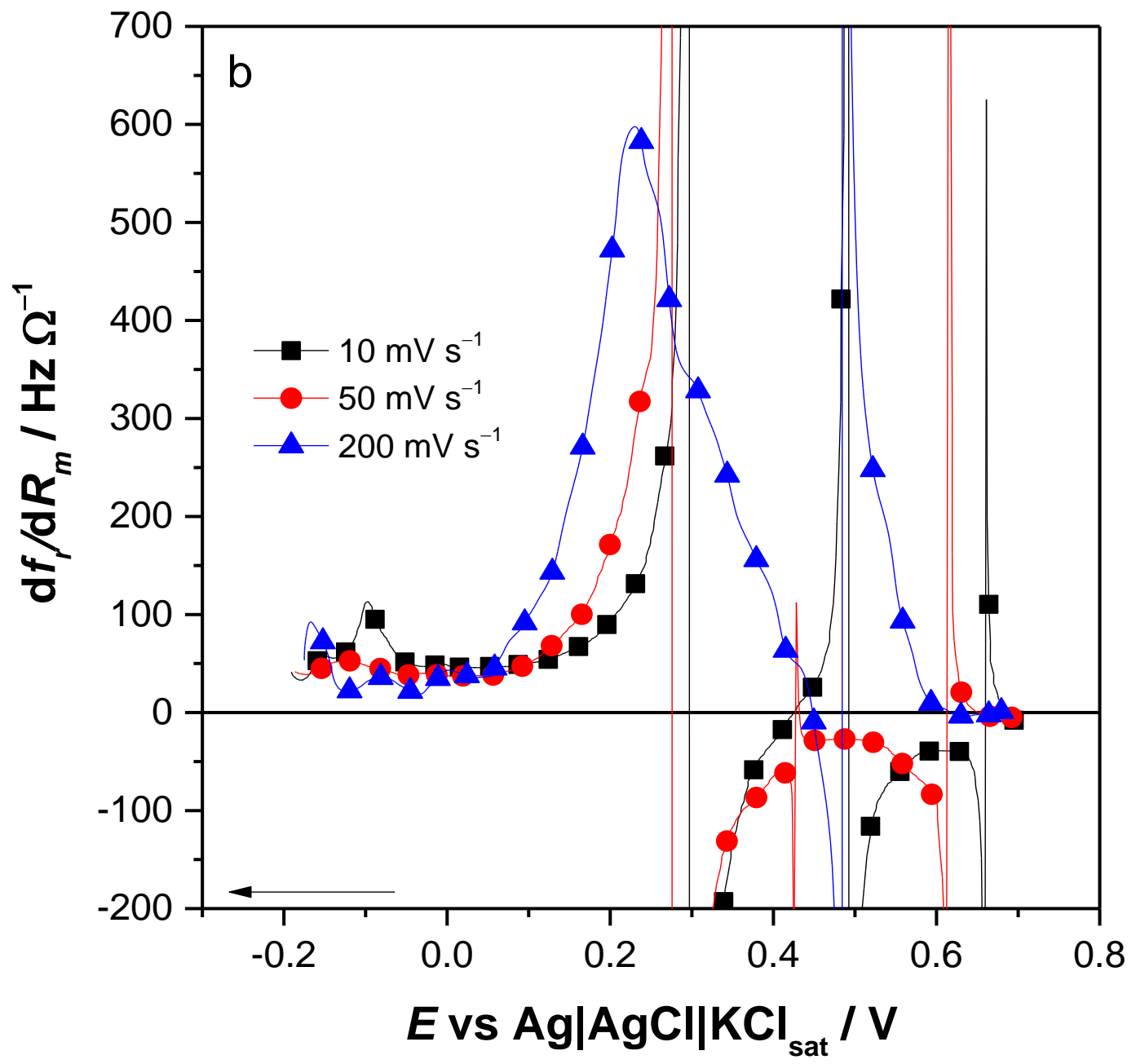

Fig. 5b 


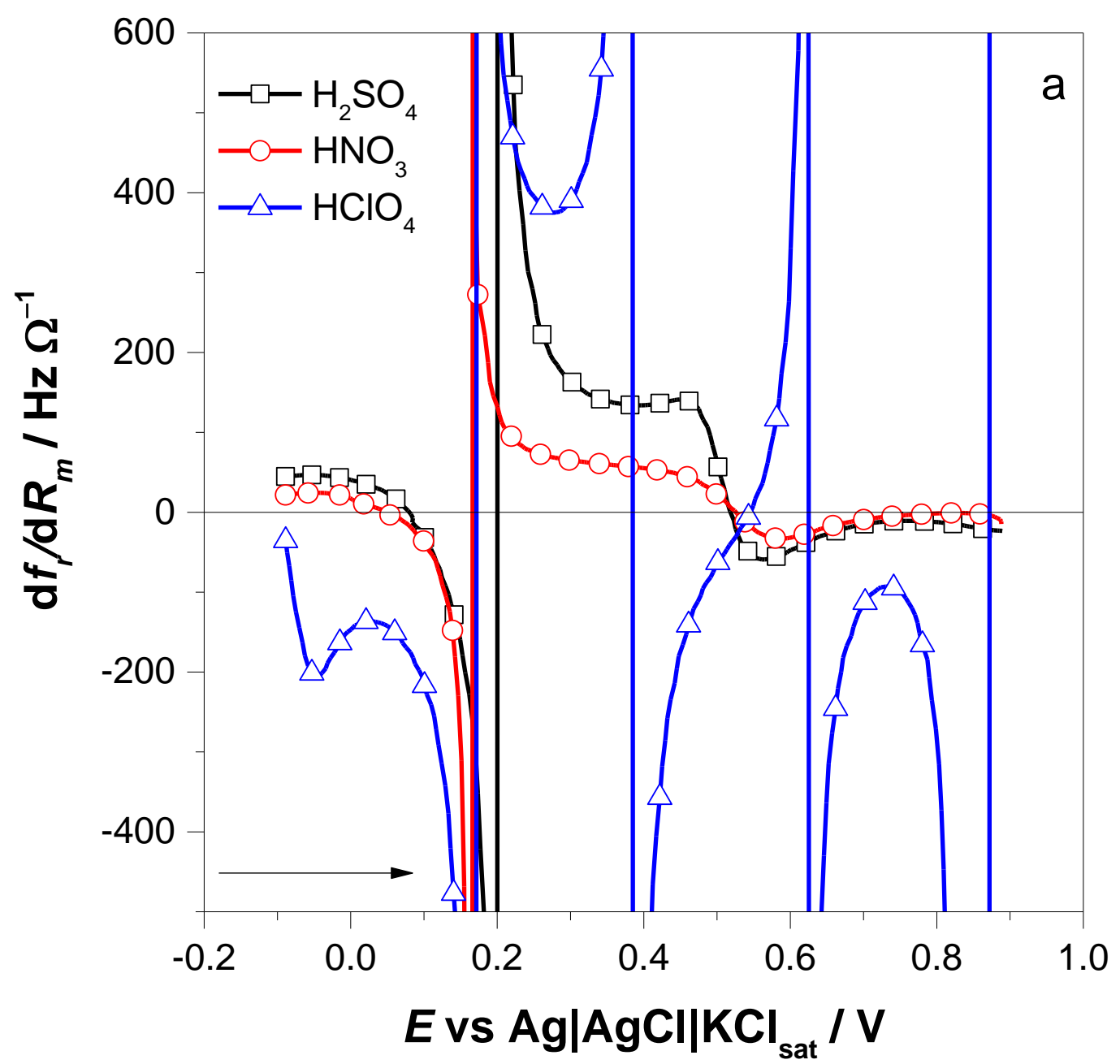

Fig. 6a 


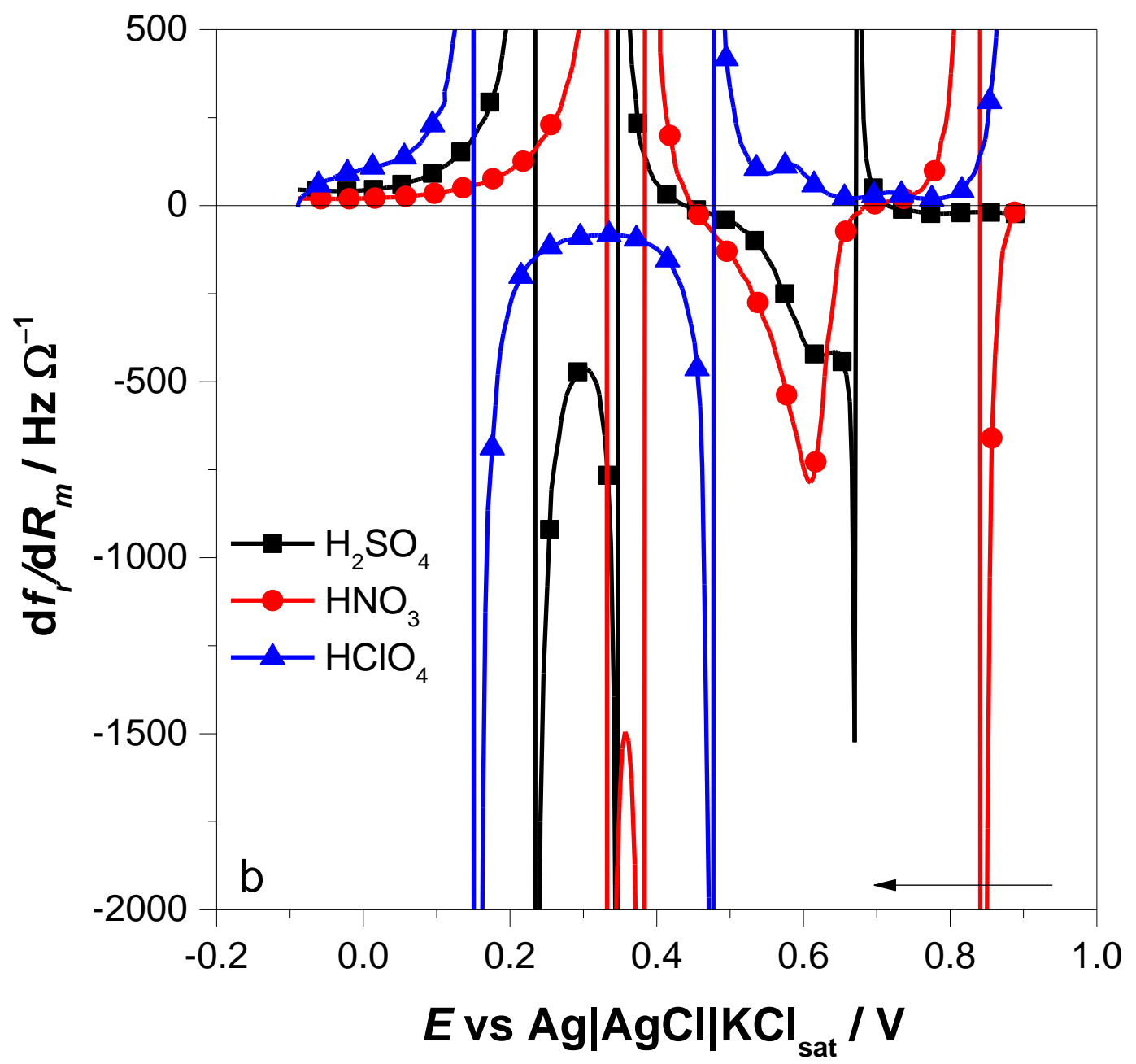

Fig. 6b 


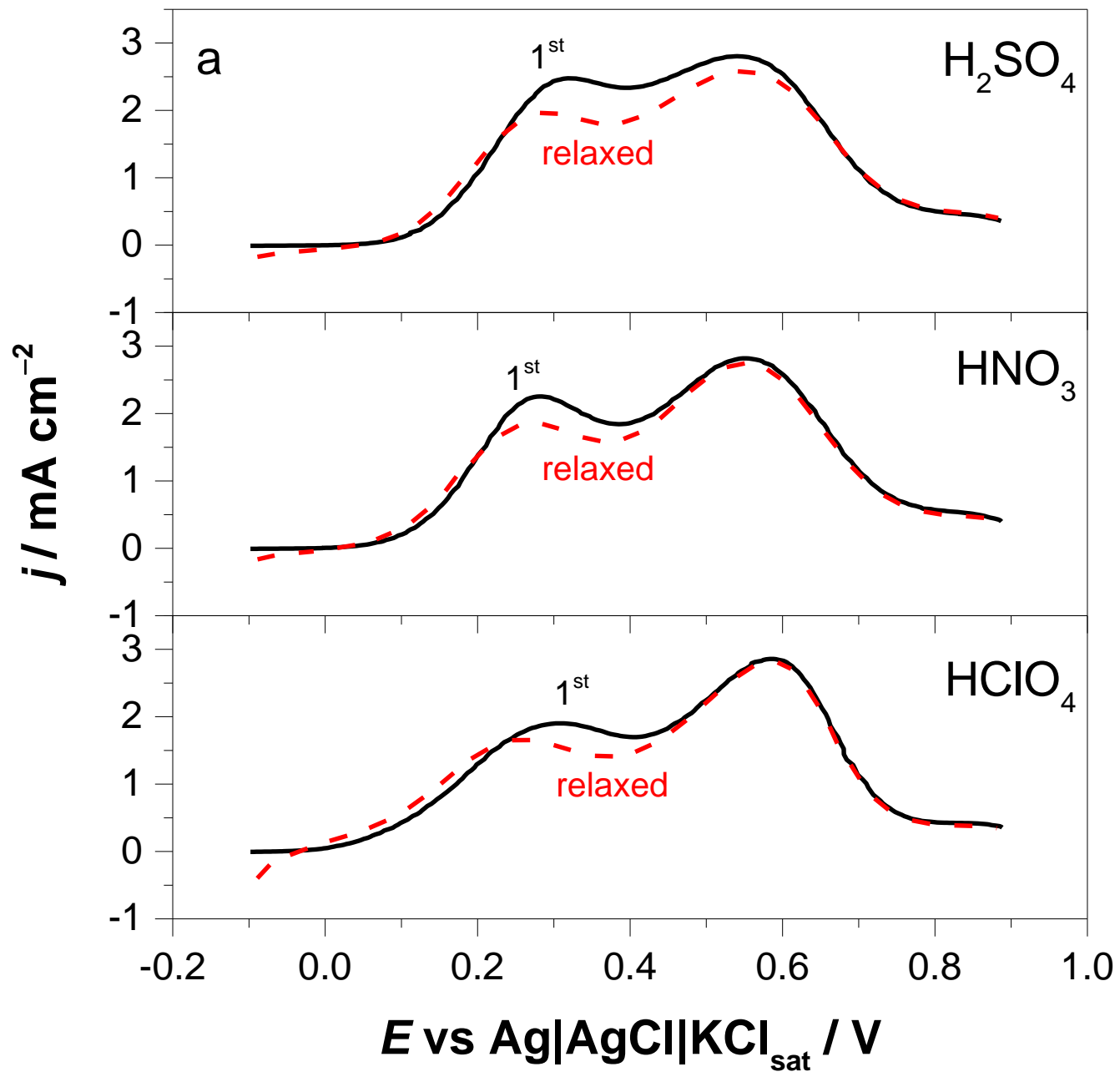

Fig. 7a 


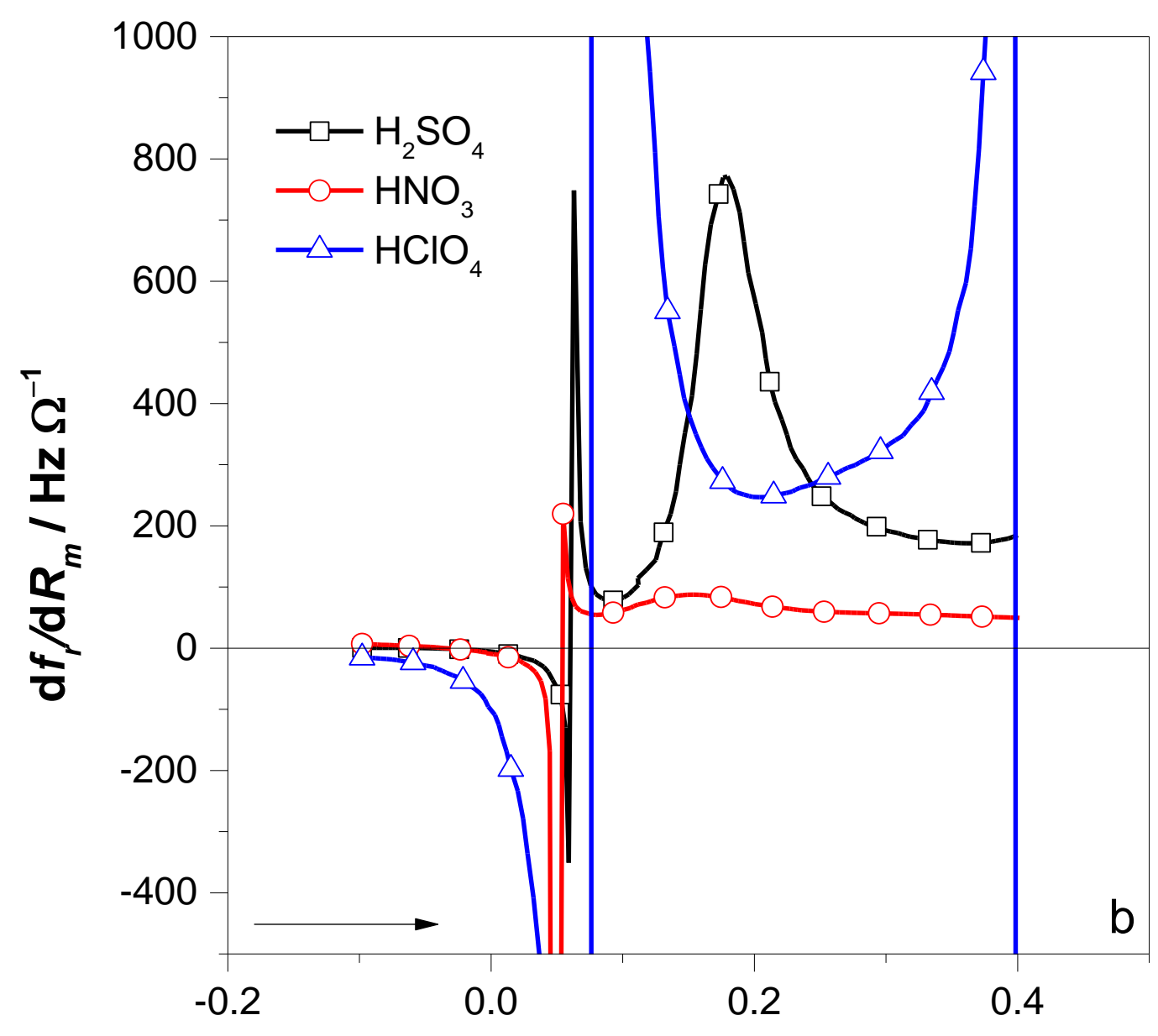

E vs $\mathrm{Ag}|\mathrm{AgCl}| \mathrm{KCl}_{\text {sat }} / \mathrm{V}$

Fig. 7b 